\title{
Research Square \\ Do Leonardo Da Vinci's Drawings, Room Acoustics And Radio Astronomy Have Anything In Common?
}

Andrzej Kulowski ( $\sim$ kulowski@pg.edu.pl)

Gdańsk University of Technology https://orcid.org/0000-0001-7003-9515

\section{Research Article}

Keywords: Leonardo da Vinci, caustic, spherical reflector, room acoustics, Arecibo, FAST

Posted Date: January 3rd, 2022

DOI: https://doi.org/10.21203/rs.3.rs-1206026/v1

License: (c) (i) This work is licensed under a Creative Commons Attribution 4.0 International License. Read Full License 
Do Leonardo da Vinci’s drawings, room acoustics and radio astronomy

have anything in common?

(3)

Andrzej Kulowski, Gdańsk University of Technology, Faculty of Architecture,

ul. Gabriela Narutowicza 11/12, 80-233 Gdańsk, Poland, e-mail: kulowski@pg.edu.pl

ORCID: 0000-0001-7003-9515

\section{Abstract}

After introducing Leonardo da Vinci's (LdV) predecessors in the field of light propagation research, his drawings on the topic of focussing light through a spherical mirror are analysed.

The discovery of LdV is presented, according to which, at an infinitely distant source of rays, a small fragment of the canopy is enough to generate a focus, while the rest of the mirror forms caustics for which LdV did not indicate an application. An analytical description of the energy concentration in the focus and on the caustics is given, together with its reference to the geometric representation of the acoustic field in rooms. Using symmetry in the description of energy relations in acoustics and electromagnetism, the interference that occurs on the caustics produced by the acoustic and electromagnetic wave is discussed. It is explained why in the sound field in existing halls, instead of a whole caustic only its cusp is observed, which is perceived as a point-like sound focus. The size of the mirror aperture, shown graphically by $\mathrm{LdV}$, is determined. How the development of receiving techniques increased the mirror aperture compared to the LdV estimate is also shown. The implementation of these improvements is presented via the example of the Arecibo and FAST radio telescopes.

Key words:

Leonardo da Vinci, caustic; spherical reflector; room acoustics; Arecibo; FAST 


\section{Introduction}

Early considerations about the propagation of light lie at the beginning of the research discipline that has developed into today's physics. One of the earliest accounts on optics, i.e. the use of instruments interfering with the course of light, is the story from ancient times about Archimedes setting fire to Roman ships besieging Carthage with the use of mirrors reflecting sunlight [1]. A later treatise by Ptolemy from the 2nd century AD is another significant work of the antiquity period concerning the study of optics [2]. The scientific considerations he initiated were continued in the Middle Ages in the Islamic world. Leonardo da Vinci (LdV) carried out his works in reference to this tradition [3]. He paid particular attention to the application of the rules of geometric optics in architecture, painting and graphics, including studies in the field of perspective and chiaroscuro.

Leonardo's sketches on optics include studies of a particular form of focussing rays of light, nowadays known as caustics. In the convention of geometric optics, caustics is a surface formed by rays tangent to it after reflection from a concave surface or as a result of propagation in an inhomogeneous medium. Under certain circumstances, a cusp may form on the caustics. In the mathematical description of caustics, it corresponds to a singularity, i.e. the parameters of the field of rays at this point tend to infinity. The physical counterpart of the caustic cusp is the focus of the mirror. The focus can also form without a caustic accompanying it, but it only applies to a few specific cases, among them a source in the centre of a spher- 
47 ical reflector, a parabolic reflector with an infinitely distant source on its geometric axis, or an ellipsoidal reflector with a source in one of its foci.

Leonardo showed that with an infinitely distant light source, only a small part of the spherical mirror is involved in creating the focus. The remainder of the mirror only forms caustics and is useless for focal formation, leading to important practical conclusions. The idea of focussing light in this way is attributed to Archimedes, who lived many centuries earlier, but the quantitative analysis shown graphically in Fig. 2 is Leonardo's personal contribution to the study of the principle of the operation of a concave mirror.

Against this historical background, the article discusses the formation of foci and caustics in the acoustic field and in the electromagnetic field. Observations of room acoustics indicate that in the audible frequency range, caustics are so blurred by diffuse sound, wave reflections and interference that it is reduced to its singularity. The observed form of caustics is then a point-like focus of sound. This occurs when the wavelength is of the same order or slightly shorter than that of the objects in the acoustic field, which is typical for rooms. When the wavelength is much shorter than the objects in the wave field, the blur effect is much smaller and the caustics act as a clearly identified energy focus area. Caustics formed in this way are present in many fields of technology and science concerning the propagation of light, ultrasounds and electromagnetic waves, e.g. hydroacoustics, aeroacoustics, laser technology, and even radio astronomy [4], [5], [6]. 
Based on the inspiration of caustic drawings in LdV's works and his considerations on

67

focussing light by a concave mirror, the article presents a mathematical description of the ef-

fect of focussing rays. Against this background, the phenomena occurring on caustics in acoustic and electromagnetic fields are presented, taking into account their wave nature.

The main goal of this paper is to investigate the extent to which LdV observations of the formation of caustics and foci are present in modern technology. The article shows how LdV's estimate of a mirror aperture has expanded as radio waves receiving techniques have developed. The presence of Leonard's thoughts in these activities is demonstrated through the example of the large radio telescopes in Arecibo (Puerto Rico) and Dawodang (China).

\section{Caustics in the legacy of Leonardo da Vinci}

The drawings of caustics in Leonardo da Vinci's notes refer to his research in the field of optics in the years 1510-1515 [7], [8]. You can find in them many sketches of caustics at different stages of their formation, the most complete drawing of caustics is shown in Fig. 1. Leonardo made his drawing 500 years ago with such competence that in the article it is quoted as a perfectly valid example of applying the principles of geometric optics in the formation of caustics. 

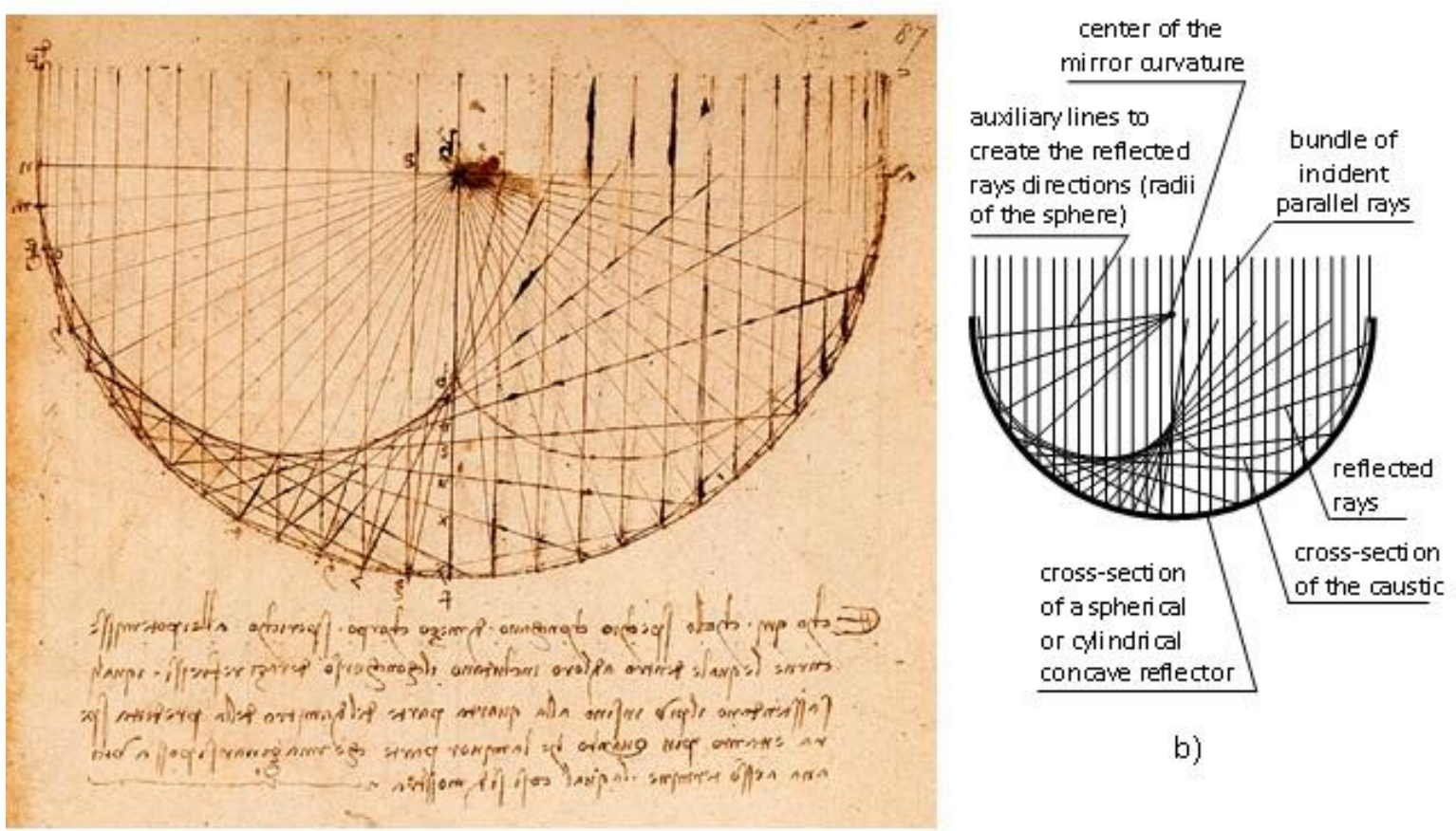

b)

a)
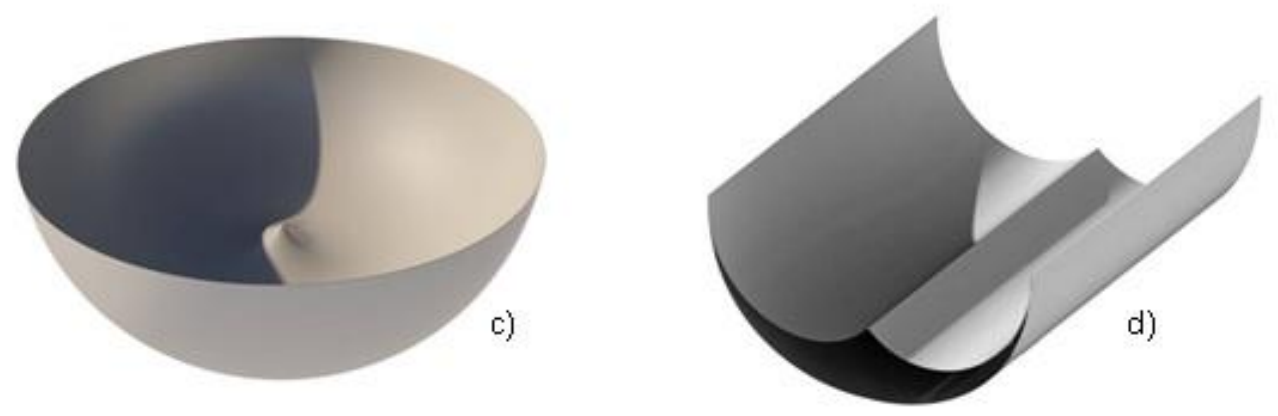

Fig. 1. a) Drawing of caustic from Leonardo da Vinci's sketchbook. The note below the picture in Fig. that has the shallower curve will concentrate the largest number of reflected rays onto a focal point, and "as a consequence, it will kindle a fire with greater rapidity and force" [9]. b) Details of Leonardo's drawing, c), d) 3D views of the caustics created by spherical and cylindrical concave mirrors [10]. 
Leonardo was interested in the potential utility of concave mirrors as sources of heat, and the purpose of his research was to assess the focussing properties of a spherical mirror. Fig. 2 shows the two mirrors differing in the depth of the canopy referred to in his reverse script in Fig. 1a. In his later works, Leonardo also planned to use the effect of focussing sunlight to heat or even boil water [11].

In light of today's level of knowledge, Leonardo's concept is obvious. However, he lived 500 years ago and the accuracy of his explanations must be considered admirable. The further part of the article shows that even in areas as distant from optics as room acoustics and radio astronomy, Leonardo da Vinci's concept can be found.

According to modern technical terminology, the fraction of the total energy incident on the mirror that is available at the receiver is called the mirror aperture. For the purposes of this article, the ratio of this area to the area of a full hemispherical mirror was adopted as the relative measure of aperture. Assuming the propagation and reflection of the rays are lossless, the relative aperture of the lower mirror shown in Fig. 2 is approximately $0.4 \%$ (Eqs. (1), (2)). For the opening angle $\varphi=10^{\circ}$ (Fig. 3), the arc length $\mathrm{r}$ is

$$
r=\frac{\varphi / 2}{180} \Pi R=\frac{\Pi R}{36}
$$
and the aperture in relation to the surface of the full hemispherical mirror is

$$
\frac{\mathrm{S}_{\mathrm{a}}}{\mathrm{S}_{\mathrm{m}}}=\frac{\Pi \mathrm{r}^{2}}{2 \Pi \mathrm{R}^{2}}=\frac{1}{2}\left(\frac{\Pi}{36}\right)^{2}=0.0038 \cong 0.4 \%
$$




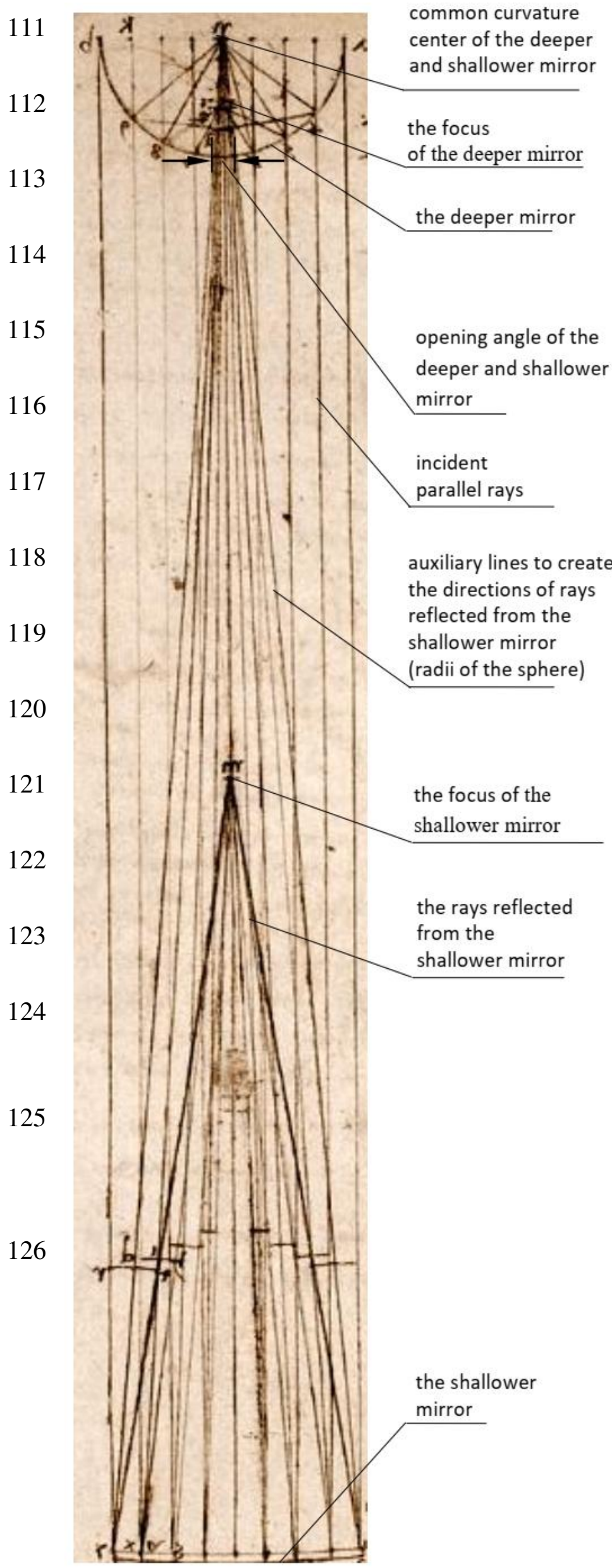

\section{Analytic description of energy \\ concentration on the caustic}

The LdV sketches present the effect of the energy concentration on a caustic in a graphical form. This section gives a quantitative assessment of this effect in an analytical form, using the original LdV drawing.

Consider the rays coming from an infinitely distant source and falling on a hemispherical mirror as a collimated beam (Fig. 1a). After the reflection, the rays form the caustic described by Eq.

(3) [12].

$\left\{\begin{array}{l}\mathrm{x}(\theta)=\mathrm{R} \cos ^{3}(\theta) \\ y(\theta)=\frac{\mathrm{R}}{2}\left(2 \sin ^{3}(\theta)-3 \sin (\theta)\right)\end{array} 0 \leq \theta \leq \Pi\right.$

Fig. 2. Illustration of Leonardo's concept, in which a shallower mirror (bottom) concentrates a larger number of rays than the mirror with a deeper bowl of the same diameter (top) [9]. 

rings.

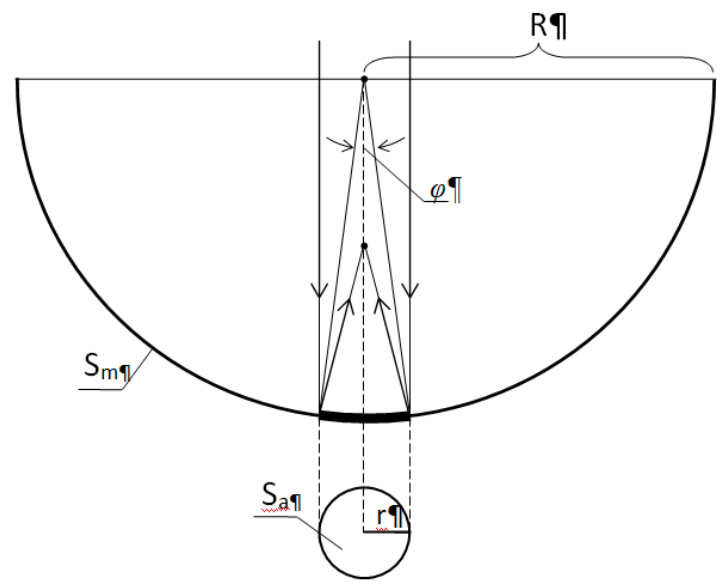

Fig. 3. Aperture of the shallower mirror from Fig. 2. $S_{m}$, R: area and radius of the full hemispherical mir-

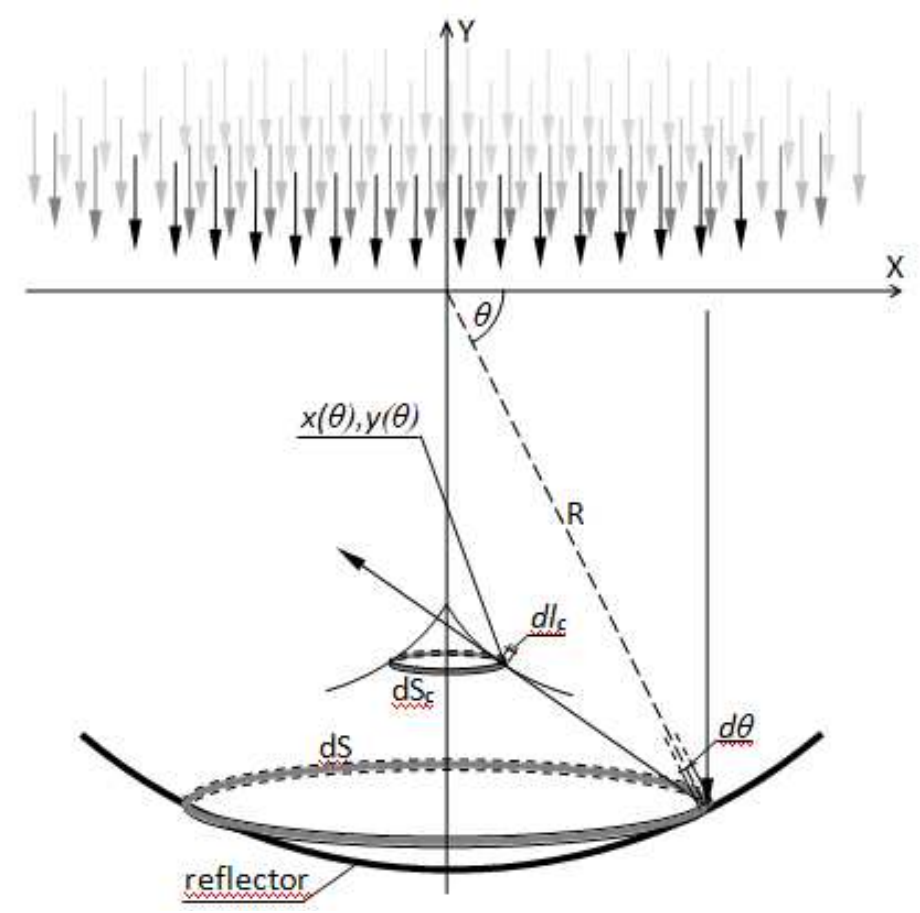

Fig. 4. Caustic formed by rays incident on a hemispherical reflector. R: radius of the reflector, $\mathrm{dS}, \mathrm{dS}_{\mathrm{c}}$ : ring on the reflector and on the caustic, $x(\theta), y(\theta)$ : Cartesian coordinates of the caustic (Eq. (3)), $d l_{c}$ : the element of the section of the caustic [13] 
148 The circumference and the width of the ring $\mathrm{dS}$ are $2 \Pi \operatorname{R} \cos (\theta)$ and $\operatorname{Rin}(\theta) \mathrm{d} \theta$, so

149

$$
d S=2 \Pi \mathrm{R}^{2} \cos (\theta) \sin (\theta) d \theta
$$

150 Likewise, the circumference and the width of the ring $d S_{c}$ are $2 \Pi x(\theta)$ and $d l_{c}$, so

$$
d S_{c}=2 \Pi x(\theta) d l_{c}
$$

152 where $d l_{c}$ is the element of a section of a caustic

$$
d l_{c}=\sqrt{\left(\frac{d x(\theta)}{d(\theta)}\right)^{2}+\left(\frac{d y(\theta)}{d(\theta)}\right)^{2}} d \theta
$$

154 and the derivatives over $\theta$ of $x(\theta), y(\theta)$ are

$$
\left\{\begin{array}{l}
\frac{d x}{d \theta}=-3 \mathrm{R} \cos ^{2}(\theta) \sin (\theta) \\
\frac{d y}{d \theta}=3 \mathrm{R} \sin ^{2}(\theta) \cos (\theta)-\frac{3}{2} \mathrm{R} \cos (\theta)
\end{array}\right.
$$

156 An elementary transformation gives

$$
\sqrt{\left(\frac{d x(\theta)}{d(\theta)}\right)^{2}+\left(\frac{d y(\theta)}{d(\theta)}\right)^{2}}=\frac{3}{2} R \cos (\theta)
$$

158 Substitution of Eq. (7) to Eq. (6) yields

$$
d l_{c}=\frac{3}{2} \mathrm{R} \cos (\theta) d \theta
$$

160 so

$$
d S_{c}=3 \Pi \mathrm{R}^{2} \cos ^{4}(\theta) d \theta
$$

161 Finally, if the rays incident on the mirror are distributed evenly on the $y=0$ plane (Fig. 4), the

162 density of rays $C(\theta)$ over the caustic is

163

$$
C(\theta)=\frac{d S}{d S_{c}}=\frac{2 \sin (\theta)}{3\left|\cos ^{3}(\theta)\right|}
$$


164 As $\theta$ tends to $0.5 \Pi, \mathrm{C}(\theta)$ tends to infinity, which corresponds to the cusp formation on the caustic (Fig. 4). This singularity results from the caustic cross-sectional area $d S_{c}$ tending to zero. density of rays $C(\theta)$ in Eq. (11) multiplied by $\mathrm{I}_{\mathrm{o}}$ can be interpreted as the surface density of energy over the caustic per unit of time, i.e. the intensity of the rays $\left[\mathrm{W} / \mathrm{m}^{2}\right]$. When the absorption coefficient $\alpha$ of the reflector is taken into account, where $\alpha=0$ and $\alpha=1$ relate to a

171 total reflection and total absorption, respectively, the rays intensity is

$$
I_{c}(\theta)=\mathrm{I}_{0}(1-\alpha) C(\theta)=\mathrm{I}_{0}(1-\alpha) \frac{2 \sin (\theta)}{3\left|\cos ^{3}(\theta)\right|} \quad\left[\mathrm{W} / \mathrm{m}^{2}\right]
$$

173 The total intensity of the rays over the caustic $I_{c, \text { res }}(\theta)$ consists of the energy of incident rays $\mathrm{I}_{\mathrm{o}}$

174 and the energy of the reflected rays condensed on the caustic.

$$
I_{c, \text { res }}(\theta)=\mathrm{I}_{\mathrm{o}}+\mathrm{I}_{\mathrm{o}}(1-\alpha) \frac{2 \sin (\theta)}{3\left|\cos ^{3}(\theta)\right|}=\mathrm{I}_{\mathrm{o}}\left(1+(1-\alpha) \frac{2 \sin (\theta)}{3\left|\cos ^{3}(\theta)\right|}\right)
$$

176 The intensity level of the rays on the caustic, with $\mathrm{I}_{\mathrm{o}}$ as the reference intensity, is then $L_{c, \text { res }}(\theta)$

177 (Fig. 5).

178

$$
L_{c, \text { res }}(\theta)=10 \log \frac{I_{c, \text { res }}(\theta)}{\mathrm{I}_{\mathrm{o}}}=10 \log \left(1+(1-\alpha) \frac{2 \sin (\theta)}{3\left|\cos ^{3}(\theta)\right|}\right) \quad[\mathrm{dB}]
$$




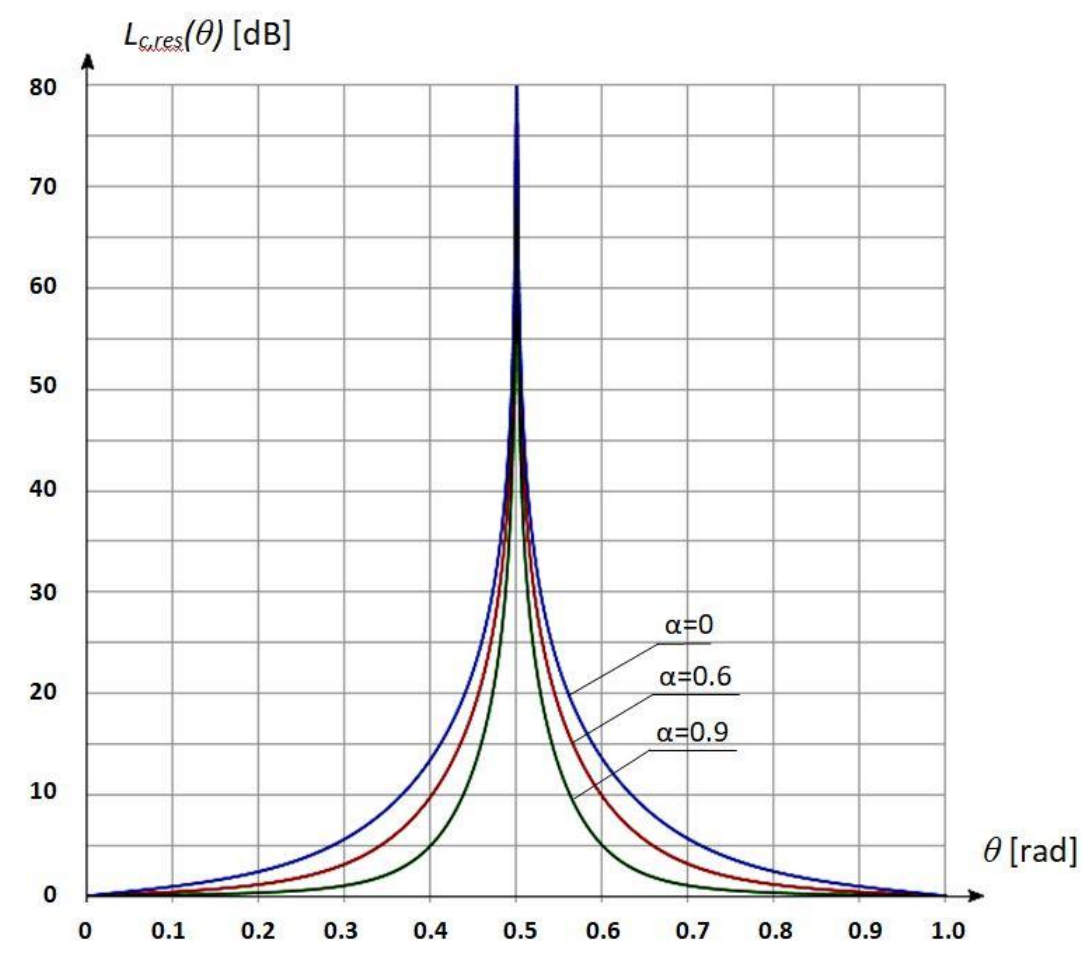

Fig. 5. Rays' intensity level $L_{c, \text { res }}(\theta)[\mathrm{dB}]$ on the caustic. $\alpha$ : absorption coefficient of the reflector [12].

\section{Caustics in the wave field}

193 based on the geometrical approach. Despite the roots that are distant in time, this approach is

194 a fully functional model of energy propagation, currently used, for example, in room acous-

195 tics, optics and radio communication. This section describes the formation of caustics in a

196 wave field, the manifestation of which is the interference of the incident wave with the wave

197 reflected from the mirror. 
200 the plane $y=0$ (Fig. 6). Propagating deep into the reflector, the wave interferes with the re-

201 flected wave. According to the law of reflection, the reflected wave is tangent to the caustic.

202 The distances SKN and SLMN travelled by the incident and reflected waves are

$$
\begin{gathered}
\mathrm{S}_{\mathrm{KN}}=\frac{\mathrm{R}}{2}\left|2 \sin ^{3} \theta-3 \sin \theta\right|=\frac{\mathrm{R}}{2}\left(3 \sin \theta-2 \sin ^{3} \theta\right), 0 \geq \theta \geq \Pi \\
\mathrm{S}_{\mathrm{LMN}}=\mathrm{R} \sin \theta+\sqrt{\left(\mathrm{R} \cos \theta-\mathrm{R} \cos ^{3} \theta\right)^{2}+\left(-\mathrm{R} \sin \theta-\left(\frac{\mathrm{R}}{2}\left(2 \sin ^{3} \theta-3 \sin \theta\right)\right)\right)^{2}}=\mathrm{R} \sin \theta+\sqrt{\left(\frac{\mathrm{R}}{2} \sin \theta \sin 2 \theta\right)^{2}+\left(\frac{\mathrm{R}}{2} \sin \theta \cos 2 \theta\right)^{2}}=
\end{gathered}
$$

204

205

206

207

208

209

210

211

212

213

214

215

216

tromagnetic waves using the same equations, differing only in the physical interpretation of

$$
\mathrm{R} \sin \theta+\frac{\mathrm{R}}{2} \sin \theta \sqrt{(\sin 2 \theta)^{2}+(\cos 2 \theta)^{2}}=\frac{3}{2} \mathrm{R} \sin \theta, \quad 0 \geq \theta \geq \Pi
$$

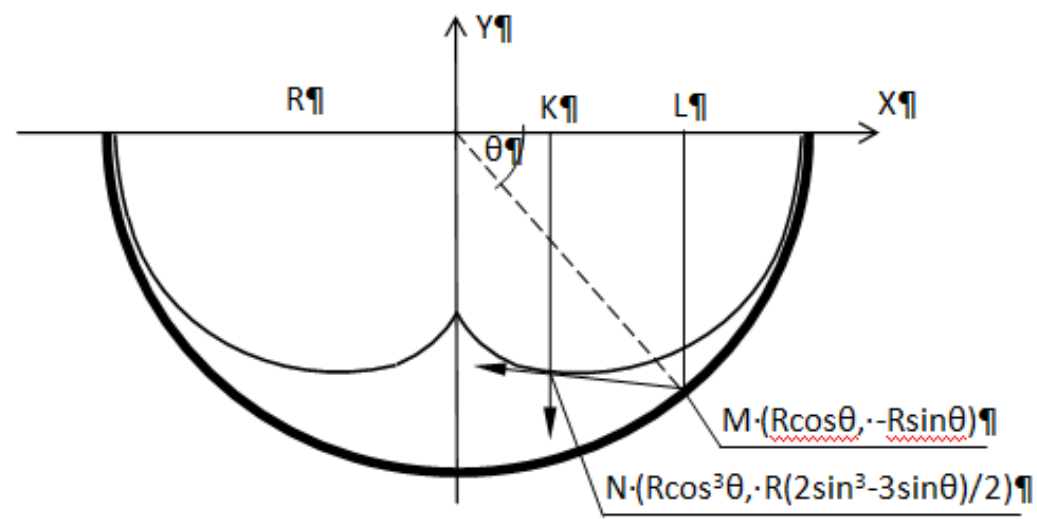

Fig. 6. Directions of the incident and reflected waves $\mathrm{KN}$ and LMN overlapping each other on the caustics. R: radius of the reflector [12]

In spite of the essentially different nature of acoustic and electromagnetic waves, the general principles of wave motion describe the energetic relationships of acoustic and elec-

217 the individual components. To highlight this similarity, successive equations relating to

218 acoustic and electromagnetic fields are presented side-by-side. 
220 in $\left[\mathrm{W} / \mathrm{m}^{2}\right]$, are proportional to the squared sound pressure $p^{2}$ [Pascal] and squared intensity of

221 the electric field $E[\mathrm{~V} / \mathrm{m}]$, respectively

$$
I_{s}=p^{2} /\left(\rho \mathrm{c}_{\mathrm{s}}\right) \quad I_{e}=E^{2} /\left(\mu_{\mathrm{o}} \mathrm{c}_{\ell}\right)
$$

223 where:

$224 \rho$ : density of the medium, $\left[\mathrm{kg} / \mathrm{m}^{3}\right]$,

$225 \mathrm{c}_{\mathrm{s}}$ : speed of sound (in the air at atmospheric pressure and a temperature of $15^{\circ} \mathrm{C}, \mathrm{c}_{\mathrm{s}}=331 \mathrm{~m} / \mathrm{s}$,

$$
\left.\rho c_{s}=415\left[\mathrm{~kg} /\left(\mathrm{m}^{2} \mathrm{~s}\right)\right]\right) \text {. }
$$

$\mu_{\mathrm{o}}$ : vacuum permeability $\left(\mu_{\mathrm{o}}=4 \Pi 10^{-7},[\mathrm{H} / \mathrm{m}]\right)$,

$\mathrm{c}_{\ell}$ : speed of light $\left(\mathrm{c}_{\iota}=3 * 10^{8}[\mathrm{~m} / \mathrm{s}]\right)$.

230 So the amplitude of the sound pressure $\overline{p_{c}(\theta)}$ and the amplitude $\overline{E_{c}(\theta)}$ of the electric field's in-

231 tensity condensed on the caustic are

$$
\overline{p_{c}(\theta)}=\sqrt{l_{c, s}(\theta) \mathrm{pc}_{\mathrm{s}}}=\sqrt{I_{o} \rho \mathrm{c}_{\mathrm{s}}} \sqrt{\frac{2(1-\alpha) \sin \theta)}{3\left|\cos ^{3}(\theta)\right|}} \quad \overline{E_{c}(\theta)}=\sqrt{I_{c, e m}(\theta) \mu_{0} \mathrm{c}_{\iota}}=\sqrt{l_{\mathrm{em}} \mu_{0} \mathrm{c}_{\iota}} \sqrt{\frac{2 \Re \sin (\theta)}{3\left|\cos ^{3}(\theta)\right|}}
$$

233 where:

$234 \mathrm{I}_{c, \mathrm{~s}}(\theta)$ : sound intensity on the caustic, $\left[\mathrm{W} / \mathrm{m}^{2}\right]$,

$235 \mathrm{I}_{\mathrm{c}, \mathrm{em}}(\theta)$ : surface power density of the electromagnetic field on the caustic, $\left[\mathrm{W} / \mathrm{m}^{2}\right]$,

$236 \mathrm{I}_{\mathrm{o}}$ : intensity of the incident sound, $\left[\mathrm{W} / \mathrm{m}^{2}\right]$,

$237 \mathrm{I}_{\mathrm{em}}$ : surface power density of the electromagnetic field, of the incident wave, $\left[\mathrm{W} / \mathrm{m}^{2}\right]$.

$\alpha$ : sound absorption coefficient, 
$239 R$ : reflection coefficient of the electric component of the electromagnetic wave.

$$
\alpha=\frac{\mathrm{I}_{\mathrm{abs}}}{\mathrm{I}_{\mathrm{i}}}=\left(\overline{\overline{\mathrm{p}_{\mathrm{abs}}}} \overline{\overline{\mathrm{p}_{\mathrm{i}}}}\right)^{2} \quad \mathcal{R}=\left(\frac{\overline{\mathrm{E}_{\mathrm{reff}}}}{\overline{\overline{\mathrm{E}}_{\mathrm{i}}}}\right)^{2}
$$

$241 \mathrm{I}_{\mathrm{abs}}, \mathrm{I}_{\mathrm{i}}$ : intensity of the absorbed and incident acoustic wave,

$242 \overline{p_{i}}, \overline{p_{\text {abs }}}$ : sound pressure amplitude of the incident and absorbed acoustic wave,

$243 \overline{E_{i}}, \overline{\mathrm{E}_{\mathrm{refl}}}$ : amplitude of the incident and reflected intensity of the electric field. For the sake of brevity, the total reflection of the electromagnetic wave, i.e. $R=1$, was adopted in the article.

Attention is drawn to the different meanings of the word "intensity" in acoustics and electromagnetism. "Intensity of the acoustic field" is proportional to $p^{2}$ (Eq.17)), while "intensity of

249 electric field" refers to $E$ in the first power (Eq.(20). The quantity proportional to $E^{2}$ is called the "surface power density of the electromagnetic field" (Eq.18)). of the incident acoustics and electromagnetic wave, respectively, in the plane $y=0$ of the re-

flector are

$$
p_{i}(\mathrm{t})=\sqrt{\mathrm{I}_{\mathrm{o}} \rho \mathrm{c}_{\mathrm{s}}} \sin \varpi t \quad E(\mathrm{t})=\sqrt{\mathrm{I}_{\mathrm{em}} \mu_{0} \mathrm{c}_{\iota}} \sin \varpi t
$$

255 where: $\omega=2 \Pi f, \quad f:$ frequency, $[\mathrm{Hz}]$. 
wave, the sound pressure is

$$
p_{K N}(\mathrm{t})=\sqrt{{ }_{l_{0}} \rho \mathrm{c}_{\mathrm{s}}} \sin \varpi\left(t+\Delta t_{1, s}\right), \quad \Delta \mathrm{t}_{1, \mathrm{~S}}=\mathrm{S}_{\mathrm{KN}} / \mathrm{c}_{\mathrm{s}}
$$

and after travelling the distance $\mathrm{S}_{\mathrm{LMN}}$ and wave condensation on the caustic according to Eq. (19)

$$
p_{L M N}(\mathrm{t}, \theta)=\sqrt{{ }_{{ }_{o} \rho c_{\mathrm{s}}}} \sqrt{\frac{2(1-\alpha) \sin (\theta)}{3\left|\cos ^{3}(\theta)\right|}} \sin \omega\left(\mathrm{t}+\Delta \mathrm{t}_{2, \mathrm{~s}}\right), \quad \Delta \mathrm{t}_{2, \mathrm{~s}}=\mathrm{S}_{\mathrm{LMN}} / \mathrm{c}_{\mathrm{s}}
$$

262 Similarly, after travelling the distance $S_{\mathrm{KN}}$ by the electromagnetic wave the intensity of the

263 electric field $E_{K N}(t)$ is

$$
E_{K N}(\mathrm{t})=\sqrt{{ }_{\mathrm{em}} \mu_{0} \mathrm{c}_{\iota}} \sin \omega\left(t+\Delta t_{1, \ell}\right), \quad \Delta \mathrm{t}_{1, \digamma}=\mathrm{S}_{\mathrm{KN}} / \mathrm{c}_{\ell}
$$

and after travelling the distance $S_{\mathrm{LMN}}$ and wave condensation on the caustic according to Eq. (20)

$$
E_{\mathrm{LMN}}(\mathrm{t}, \theta)=\sqrt{l_{\mathrm{em}} \mu_{0} \mathrm{c}_{\iota}} \sqrt{\frac{2 \sin (\theta)}{3\left|\cos ^{3}(\theta)\right|}} \sin \omega\left(t+\Delta t_{2, \ell}\right), \quad \Delta \mathrm{t}_{2,}=\mathrm{S}_{\mathrm{LMN}} / \mathrm{c}_{\iota}
$$

267 The resultant sound pressure $p_{c, r e s}(\mathrm{t}, \theta)[\mathrm{Pa}]$ and intensity of the electric field $E_{c, r e s}(\mathrm{t})[\mathrm{V} / \mathrm{m}]$ on 268 the caustic are then

$$
\begin{aligned}
& p_{c, \text { res }}(\mathrm{t}, \theta)=\sqrt{I_{\mathrm{o}} \rho \mathrm{c}_{\mathrm{s}}}\left(\sin \varpi\left(t+\Delta t_{1, s}\right)+\sqrt{\frac{2(1-\alpha) \sin \theta)}{3\left|\cos ^{3}(\theta)\right|}} \sin \varpi\left(\mathrm{t}+\Delta \mathrm{t}_{2, s}\right)\right) \\
& E_{c, \text { res }}(\mathrm{t}, \theta)=\sqrt{{ }_{\mathrm{em}} \mu_{0} \mathrm{c}_{\iota}}\left(\sin \varpi\left(t+\Delta t_{1, \ell}\right)+\sqrt{\frac{2 \sin (\theta)}{3\left|\cos ^{3}(\theta)\right|}} \sin \varpi\left(t+\Delta t_{2, \iota}\right)\right)
\end{aligned}
$$

271 The phase difference $\Delta \mathrm{t}_{1}-\Delta \mathrm{t}_{2}$ in Eqs. (33) and (34) increases with $\theta$, which causes $p_{c, \text { res }}(\mathrm{t})$ and $E_{c, \text { res }}(\mathrm{t})$ to fluctuate on the caustic over time. Fluctuations of sound pressure are described by

273 Eq. (35), which is obtained by substituting equations (15), (16) to (26), (28) and then to (33). 
274 Fluctuations of the intensity of an electric field are described by Eq. (36) which is obtained by 275 substituting equations (15), (16) to (30), (32) and then to (34).

$$
p_{c, \text { res }}(\mathrm{t}, \theta)=\sqrt{{ }_{\mathrm{o}} \rho \mathrm{c}_{\mathrm{s}}}\left[\sin \omega\left(\mathrm{t}+\frac{\mathrm{R}}{2 \mathrm{c}_{\mathrm{s}}}\left(3 \sin \theta-2 \sin ^{3} \theta\right)\right)+\sqrt{\frac{2(1-\alpha) \sin \theta)}{3\left|\cos ^{3}(\theta)\right|}} \sin \omega\left(\mathrm{t}+\frac{3 \mathrm{R}}{2 \mathrm{c}_{\mathrm{s}}} \sin \theta\right)\right]
$$

$$
E_{c, \text { res }}(\mathrm{t}, \theta)=\sqrt{{ }_{\mathrm{em}} \mu_{0} \mathrm{c}_{\iota}}\left[\sin \omega\left(\mathrm{t}+\frac{\mathrm{R}}{2 \mathrm{c}_{\iota}}\left(3 \sin \theta-2 \sin ^{3} \theta\right)\right)+\sqrt{\frac{2 \sin (\theta)}{3\left|\cos ^{3}(\theta)\right|}} \sin \omega\left(\mathrm{t}+\frac{3 \mathrm{R}}{2 \mathrm{c}_{\iota}} \sin \theta\right)\right]
$$

which results from Eqs. (37) and (38) for acoustic and electromagnetic fields, respectively.

$$
\frac{\mathrm{d}}{\mathrm{dt}} p_{c, \text { res }}(\mathrm{t}, \theta)=0 \quad \frac{\mathrm{d}}{\mathrm{dt}} E_{c, \text { res }}(\mathrm{t})=0
$$

281 For a given $\theta$, Eqs. (35) and (36) describe the fluctuations at a given point of the caustic. Solv-

282 ing Eqs. (37) and (38), i.e. finding the function $\mathrm{t}(\theta)$, determines the amplitude of the fluctua283 tions on the entire caustics (Eqs. (39) and (40)). The solution of Eq. (37) is given in the ap284 pendix in Eq. (A9), and the solution of Eq. (38) is analogous.

$$
\mathrm{t}_{\mathrm{s}}=\frac{1}{\varpi} \operatorname{arctg}\left(q_{s}\right)-\Delta \mathrm{t}_{1} \quad \mathrm{t}_{\iota}=\frac{1}{\varpi} \operatorname{arctg}\left(q_{\ell}\right)-\Delta \mathrm{t}_{1}
$$

$$
\text { where } q_{s}=\frac{\sqrt{\frac{3\left|\cos ^{3} \theta\right|}{2(1-\alpha) \sin \theta}}+\cos \left(\varpi \frac{\mathrm{R} \sin ^{3} \theta}{\mathrm{c}_{\mathrm{s}}}\right)}{\sin \left(\varpi \frac{\mathrm{R} \sin ^{3} \theta}{\mathrm{c}_{\mathrm{s}}}\right)}
$$

$$
q_{\ell}=\frac{\sqrt{\frac{3\left|\cos ^{3} \theta\right|}{2(1-\alpha) \sin \theta}}+\cos \left(\varpi \frac{R \sin ^{3} \theta}{c_{\ell}}\right)}{\sin \left(\varpi \frac{R \sin ^{3} \theta}{c_{\ell}}\right)}
$$

Substituting $t_{s}$ and $t_{l}$ into Eqs. (35) and (36), respectively, yields the maximum range of ampli-

$[\mathrm{V} / \mathrm{m}]$ over the whole caustic.

$$
p_{c, \text { res, Max }}(\theta)=\sqrt{{ }_{\mathrm{o}} \rho \mathrm{c}_{\mathrm{s}}}\left[\sin \left(\operatorname{arctg}\left(q_{s}\right)\right)+\sqrt{\frac{2(1-\alpha) \sin (\theta)}{3\left|\cos ^{3}(\theta)\right|}} \sin \left(\operatorname{arctg}\left(q_{s}\right)+\varpi \frac{R \sin ^{3} \theta}{\mathrm{c}_{\mathrm{s}}}\right)\right]
$$




$$
E_{c, \text { res, Max }}(\theta)=\sqrt{\operatorname{lem}_{\text {em }} \mu_{0} c_{\iota}}\left[\sin \left(\operatorname{arctg}\left(q_{\iota}\right)\right)+\sqrt{\frac{2 \sin \theta)}{3\left|\cos ^{3}(\theta)\right|}} \sin \left(\operatorname{arctg}\left(q_{\iota}\right)+\varpi \frac{\operatorname{Rsin}^{3} \theta}{\mathrm{c}_{\iota}}\right)\right]
$$

\section{Case studies}

The mechanism of caustic formation and the circumstances of the focal formation, a demonstration function. How the development of the receiving technique related to the detection of radio waves extended the mirror aperture estimated by LdV is also shown.

\subsection{Caustics in sound fields}

Fig. 7 a, b presents the graph of Eq. (43) for sound waves with a frequency of $f=1000$ $\mathrm{Hz}$ and $\mathrm{f}=2000 \mathrm{~Hz}$, reflected by a hemispherical reflector with the diameter of $\mathrm{D}=2 \mathrm{~m}$. In and $\lambda / D=0.085$, respectively). The directions of these waves shown in Fig. 6 therefore meet the principles of geometric optics, and the diffraction of the wave at the reflector's edge can be neglected.

$$
\overline{\mathrm{p}_{\mathrm{i}}}=\sqrt{{ }_{\mathrm{o}} \rho \mathrm{c}_{\mathrm{s}}}=\sqrt{10^{-8} * 415} \cong 0.002[\mathrm{~Pa}]
$$




$$
S P L_{i}=20 \log \left(0.002 /\left(2 * 10^{-5}\right)\right)=40[\mathrm{~dB}]
$$

312 The sound pressure $p_{c, r e s}$ (Eq. (26)) and the corresponding pressure level $S P L_{c, r e s}$ on the caus-

313 tic (Eq. (47)) fluctuate around these values. The amplitude of the fluctuations increases with

314 the increasing effect of wave condensation on the caustic (Fig. 7 a, b).

$$
S P L_{c, \text { res }}(\theta)=20 \log \left(p_{c, \text { res, max }}(\theta) /\left(2 * 10^{-5}\right)\right)
$$

316 At the cusp of the caustic, the concentrated energy of the reflected waves significantly ex-

317 ceeds the energy of the incident wave, which reduces the fluctuation effect (Fig. 7 c, d).

The result of interference outside the focus is the arrangement of nodes and antinodes formed by the superimposition of incident and reflected waves on the caustics. In real condi-

321 the reverberant field of the room. This is combined with the diffraction of the incident low

322 frequency wave at the edge of the canopy. As a result, the presence of caustics in the room is usually difficult to detect by hearing, and the audible effect of sound focussed by acoustic

324 mirrors is reduced to a point focus of sound. 


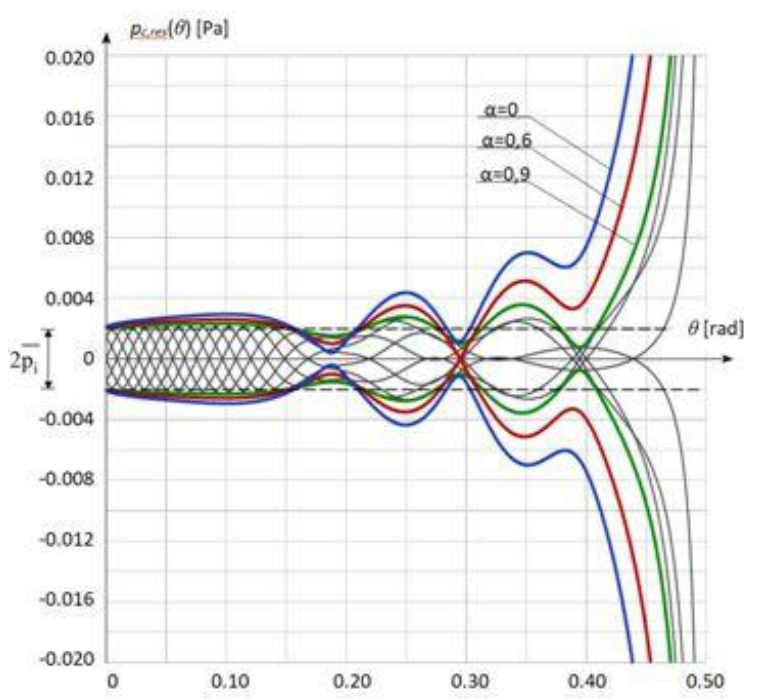

a)

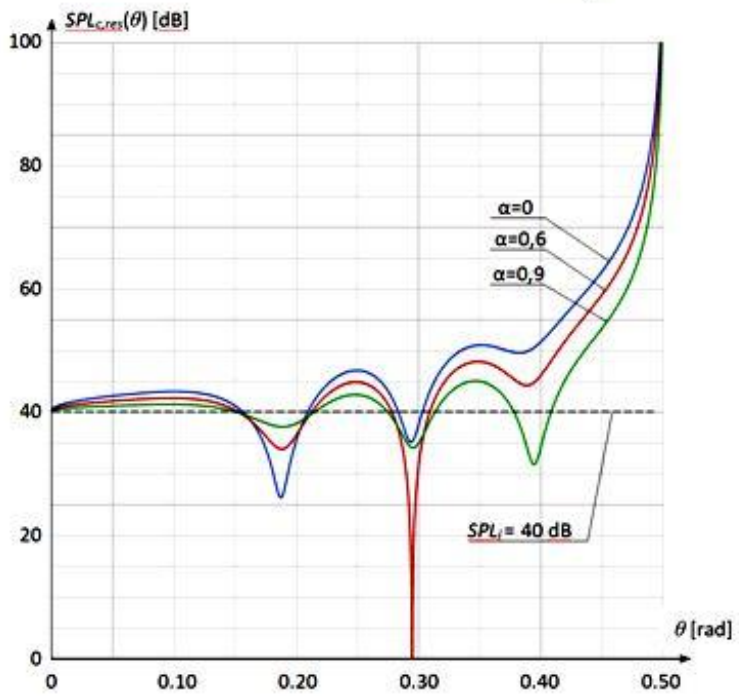

c)

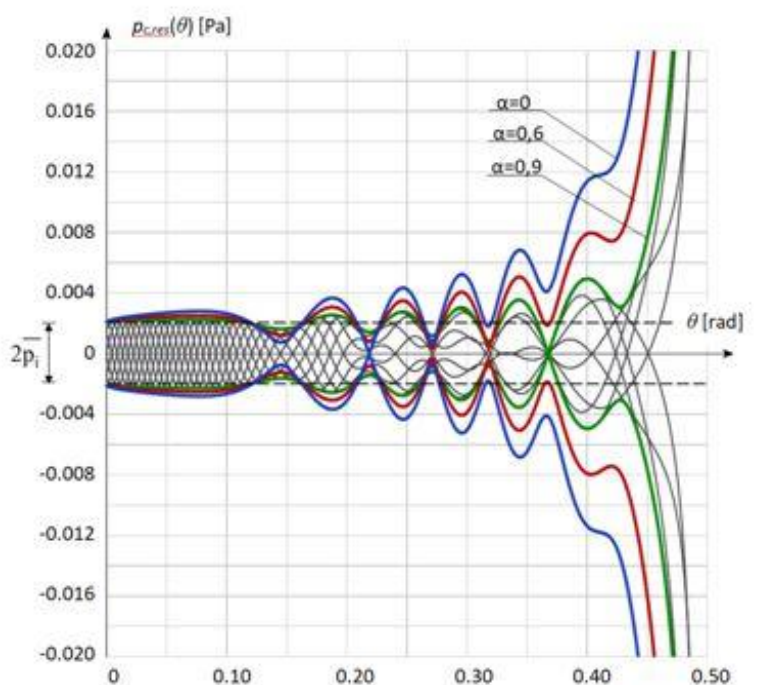

b)

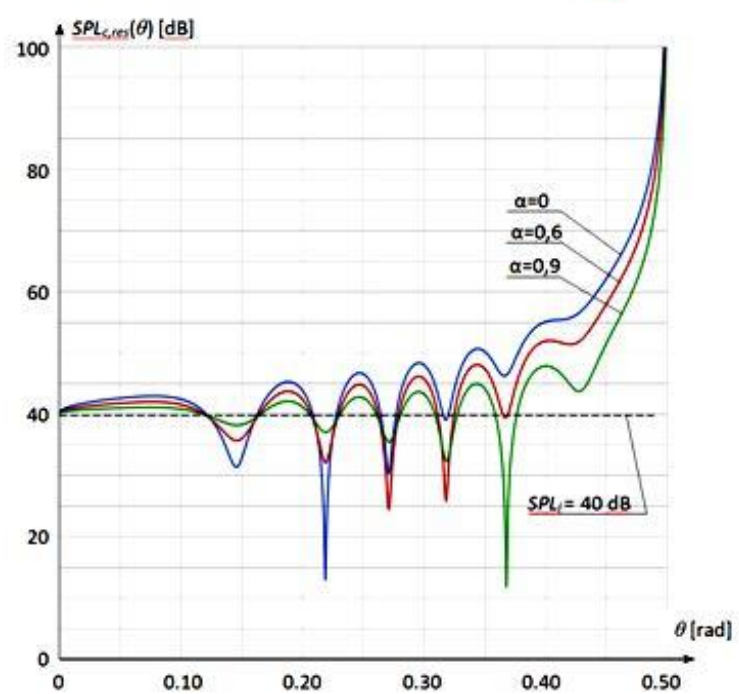

d)

Fig. 7. a), b) Resultant sound pressure of the plane waves with the frequencies $\mathrm{f}=1000 \mathrm{~Hz}$ and $\mathrm{f}=2000 \mathrm{~Hz}$, respectively, incident on a hemispherical reflector with the diameter $\mathrm{R}=1 \mathrm{~m}$ and interfering with the wave that

328 forms the caustic. $\overline{\mathrm{p}_{\mathrm{i}}}$ : amplitude of the incident wave, $\alpha$ : sound absorption coefficient of the reflector. Thin black

329 lines: sound pressure of the resultant wave $p_{c, \text { res }}(t, \theta)$ at the points in time $\mathrm{t}=0, \mathrm{~T} / 8, \ldots, 7 \mathrm{~T} / 8$ where $\mathrm{T}=1 / \mathrm{f}$, at $\alpha=0.9$. Green, red and blue lines: amplitude of fluctuations $p_{c, \text { res, } \operatorname{Max}}(\theta)$ at $\alpha=0.9, \alpha=0.6$ and $\alpha=0$, respective-

331 ly. Due to symmetry, the range $0 \leq \theta \leq \Pi / 2$ is shown. c), d) Resultant sound pressure level $S P L_{c, \text { res }}(\theta)$ of the inter- 
Fig. 7 shows how much sound amplification can be expected at the cusp of the caus-

tics. When the level of incident sound on the mirror is about $40 \mathrm{~dB}$, which corresponds to e.g. in historical times. Fig. 7 shows that in the focus, the surface sound power density may increase by approx. $45 \mathrm{~dB}$ or more, which is accounted for by a small part of the canopy. It is a approx. $10^{\circ}$. non of reflection.
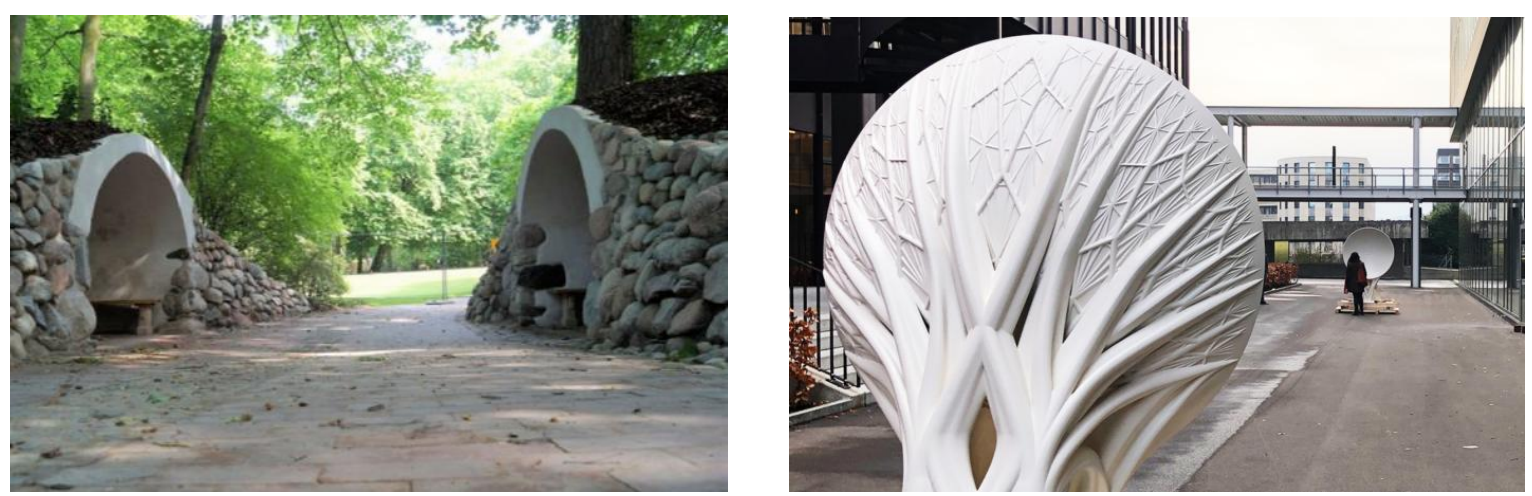

a)

b) 
Fig. 8. Outdoor installations erected to demonstrate acoustic curiosities.

a) Eighteenth-century Whispering Grottoes in Oliwa Park, Gdańsk, Poland [10], [14],

b) Contemporary outdoor installation made by 3D printing [15], [16], [17]

shown in LdV's drawings. We are talking here primarily about historical interiors with a sa-

361 cave vaults, which were the then canon of the neo-renaissance style (Fig. 10) [12].

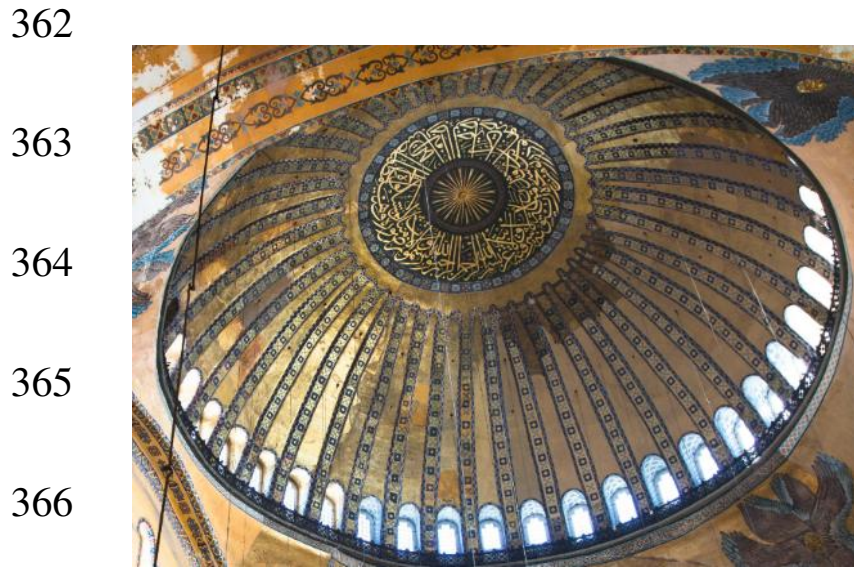

a)

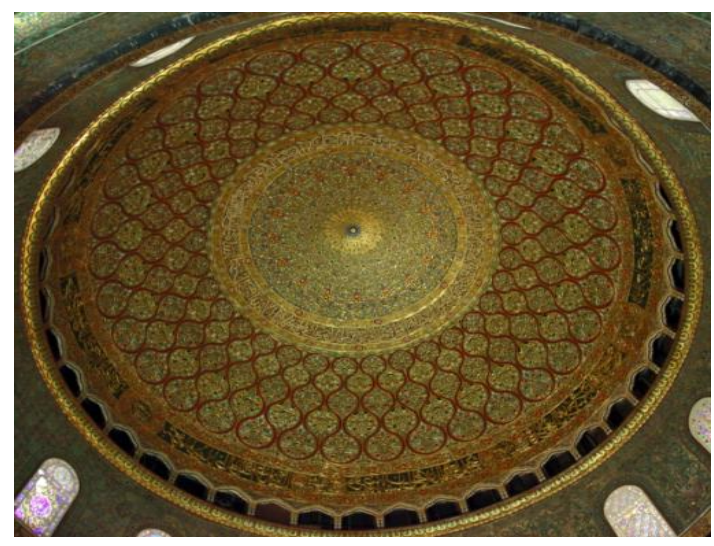

b)

Fig. 9. Historical rooms with large dome-shaped areas. 


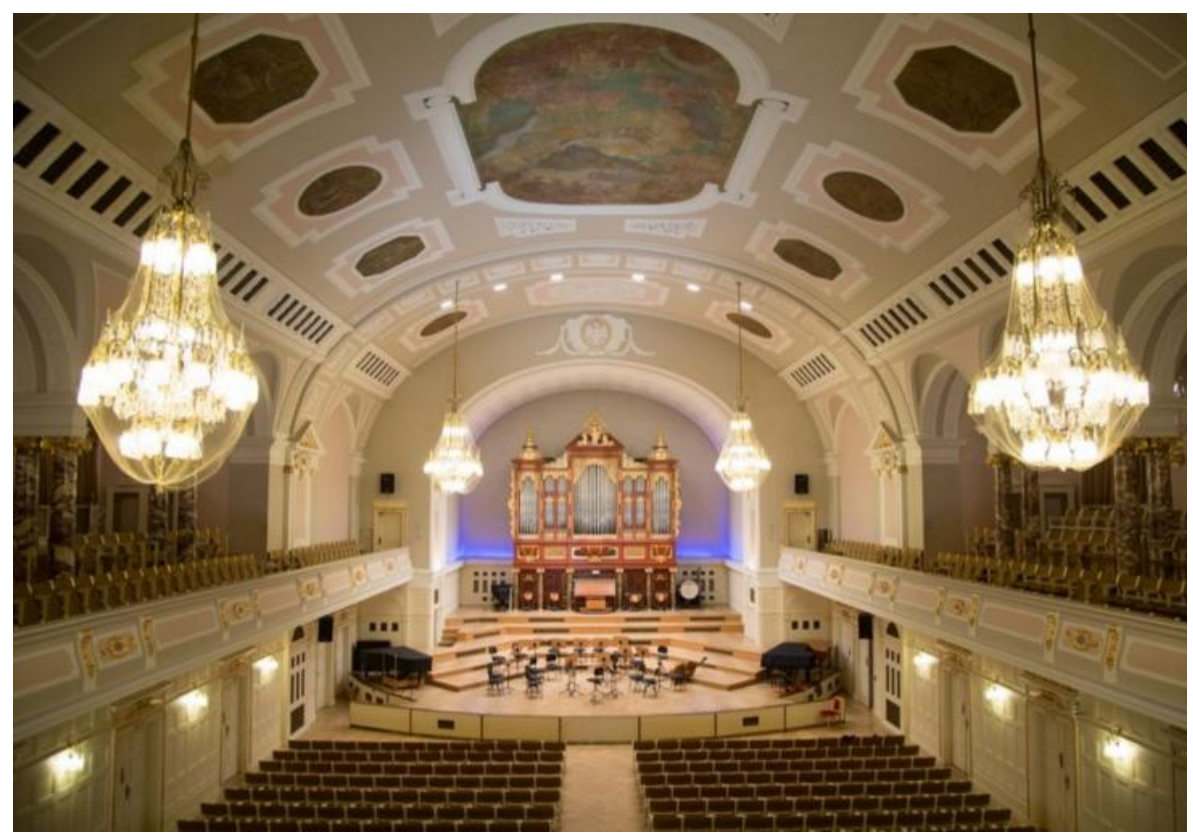

a)

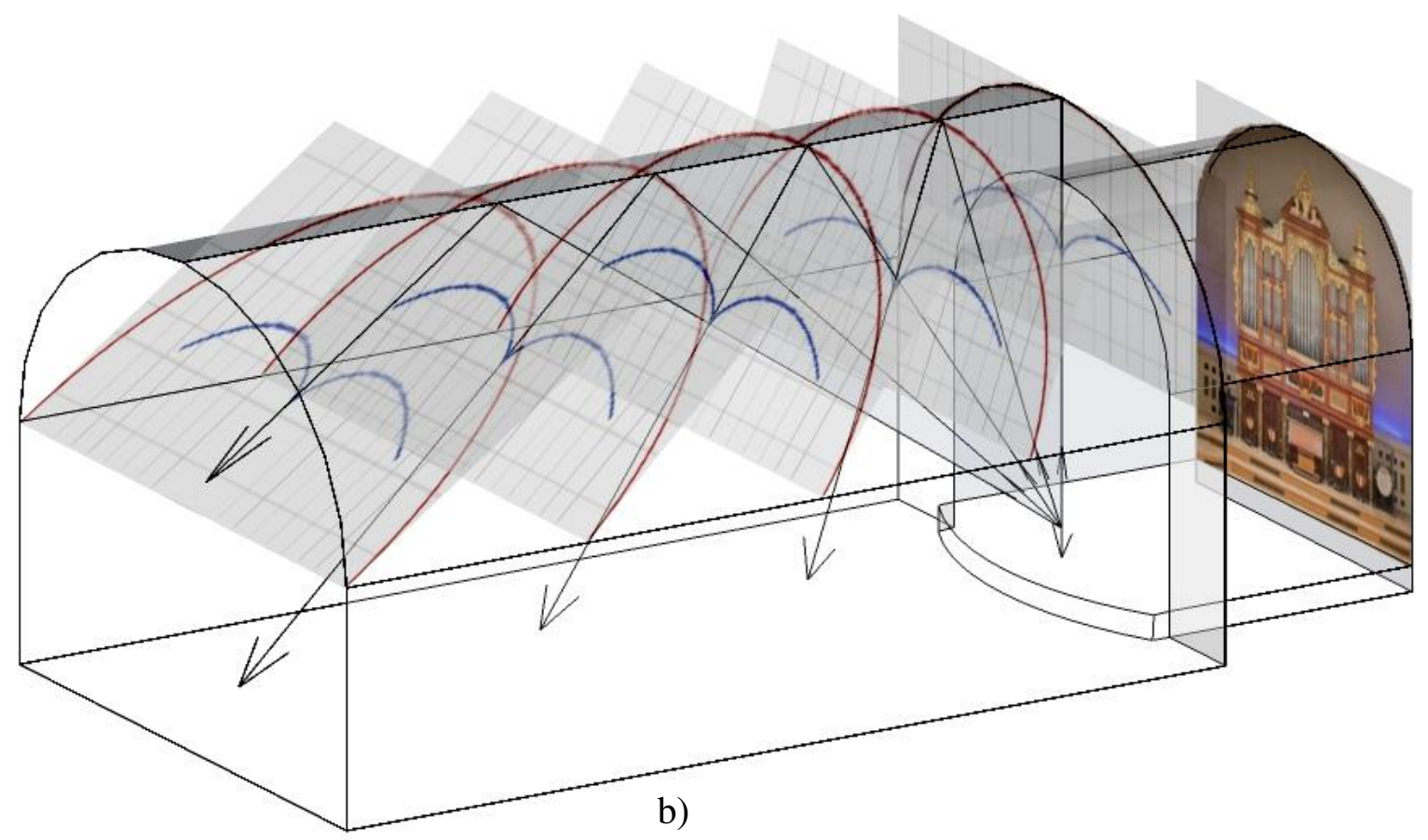

Fig. 10. a) Assembly Hall of Poznań University. This neo-renaissance building was erected according to the design of Edward Fürstenau in 1905-1910, photo courtesy of Poznań Film Commission [19].

b) Cross-sections of a 3D caustic as predicted by LdV [12]. 
372

373

374

375

376

377

378

379

380

382

383

384

\subsection{Caustics in electromagnetic fields}

Fig. 11 shows electric field fluctuations on the caustics formed by the reflector of the Arecibo radio telescope in Puerto Rico (Fig. 12). The radio telescope was put into operation in 1963 and initially the reflector aperture was small. It was significantly upgraded in 1997 by the use of the Gregorian subreflector system, which concentrates the energy of the caustics sections adjacent to the cusp into the single focal point (Fig. 13). The subreflector system consists of two shaped surfaces called secondary and tertiary reflectors hidden inside on the geodetic dome. The first is the parabolic reflector and the second constitutes the pair of elliptic reflectors (Fig. 14) [20].

The upgraded aperture of the $\mathrm{A}_{\text {Arecibo }}$ radio telescope is approx. $30,000 \mathrm{~m}^{2}$, which is approx. $7 \%$ of the hemisphere surface with a radius of $\mathrm{R}_{\text {Arecibo }}=265 \mathrm{~m}$ (Eq. (48)) [21].

$$
\frac{\mathrm{A}_{\text {Arecibo }}}{2 \Pi R_{\text {Arecibo }}^{2}}=\frac{30000}{2 \Pi 265^{2}}=0.068=6.8 \%
$$

Compared to the reflector analysed by LdV with an aperture of approx. $0.4 \%$ of the hemisphere area (see Fig. 3, Eqs. (1) and (2)), the relative aperture of the Arecibo radio telescope reflector is 17 times greater $(0.068 / 0.004=17)$, i.e. by 1 order of magnitude. This is due to the fact that, according to LdV, the energy concentrated by the reflector is contained in its focus, while the Arecibo radio telescope enlarges it by the energy of a significant part of the caustics. On December 1,2020 - a tragic day for the scientific community - the Arecibo radio telescope was destroyed due to the cables breaking and the 900-ton main platform falling onto the radio telescope's canopy. 


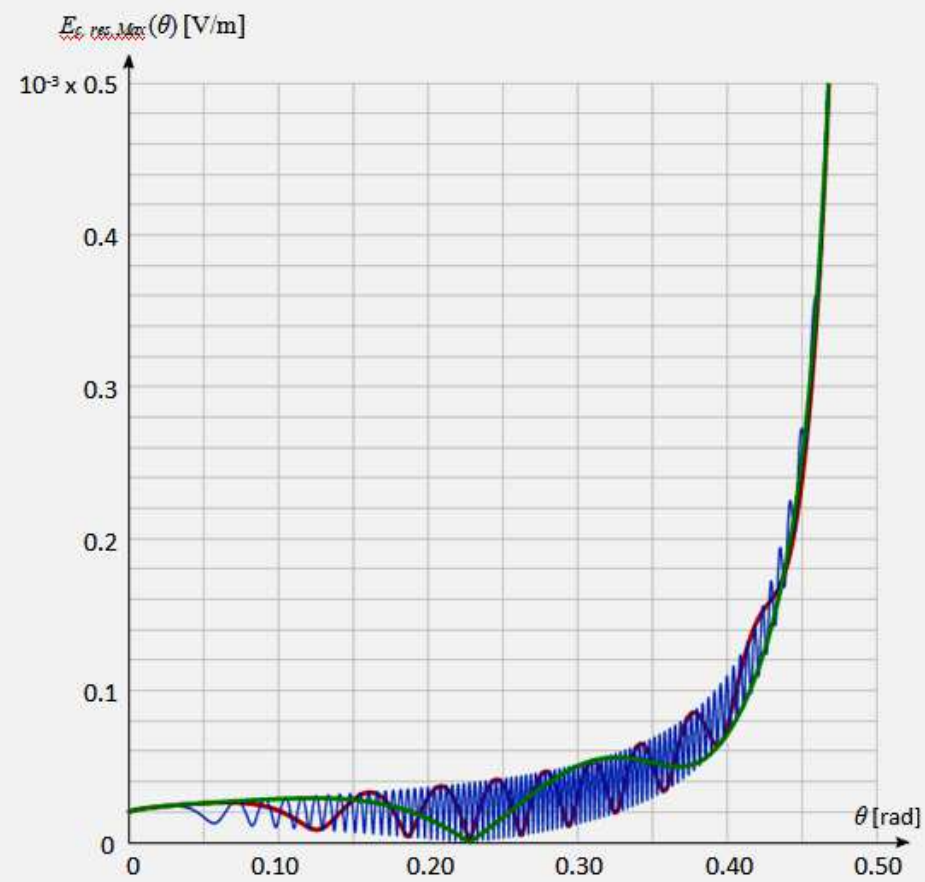

400

401 Fig. 11. Result of the interference of the plane electromagnetic wave incident on a hemispherical re-

402 flector with the diameter $\mathrm{R}=265 \mathrm{~m}$, interfering with the wave reflected from the reflector. Intensity of 403 the incident wave: $10^{-12} \mathrm{~W} / \mathrm{m}^{2}$, frequency of the wave: $2 \mathrm{MHz}, 10 \mathrm{MHz}$ and $100 \mathrm{MHz}$ (green, red and 
405

406

407

408

409

410

411
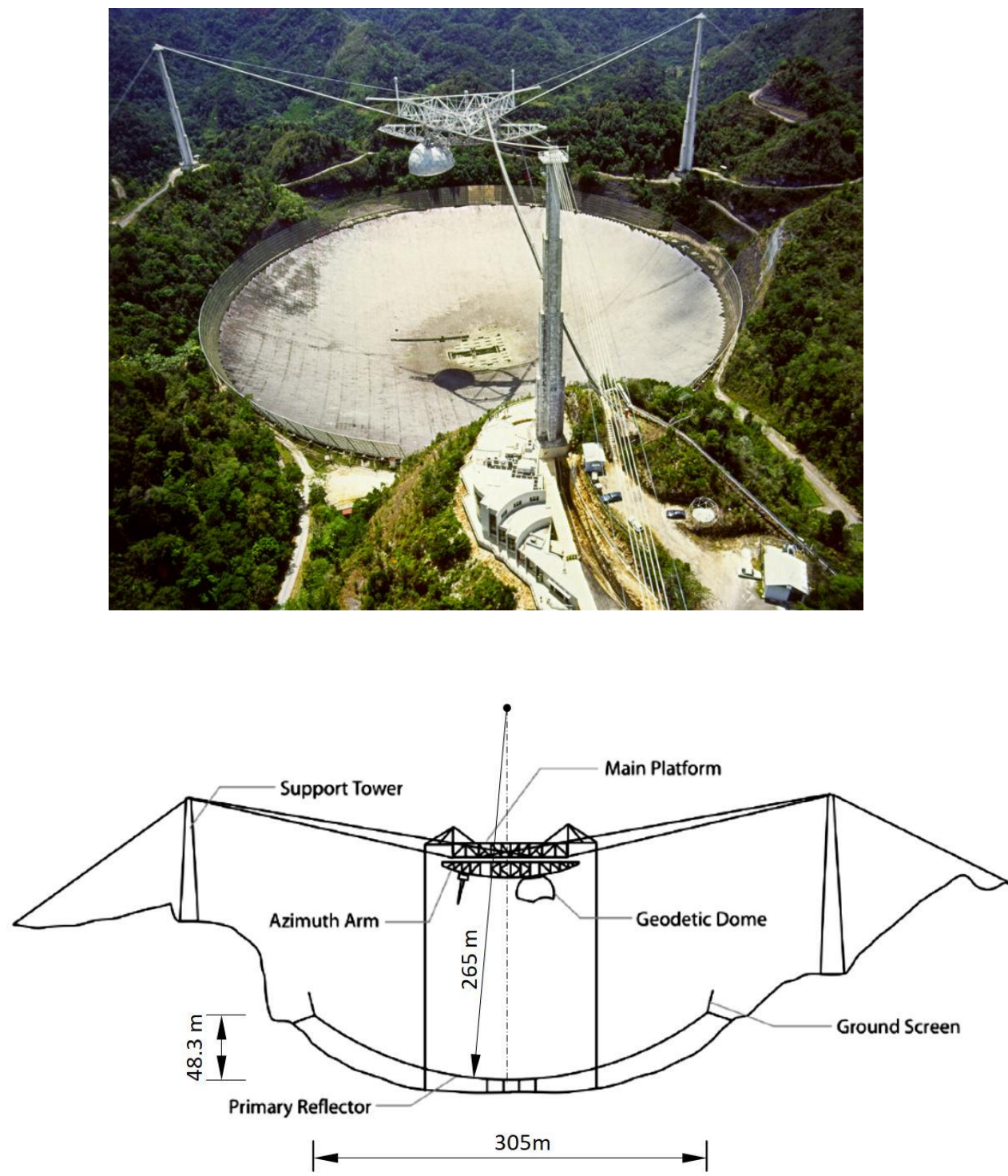

412

413 Fig. 12. Spherical radio telescope in Arecibo, Puerto Rico, photo taken before 01.12.2020 [22] 


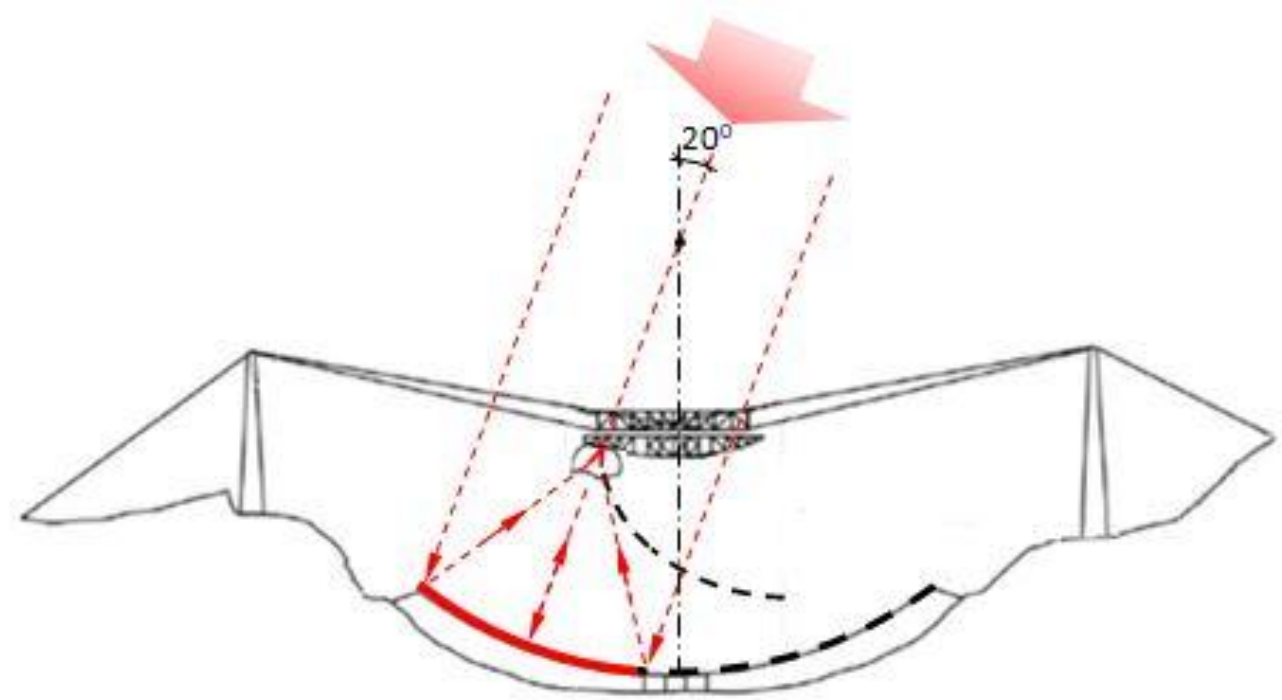

a)

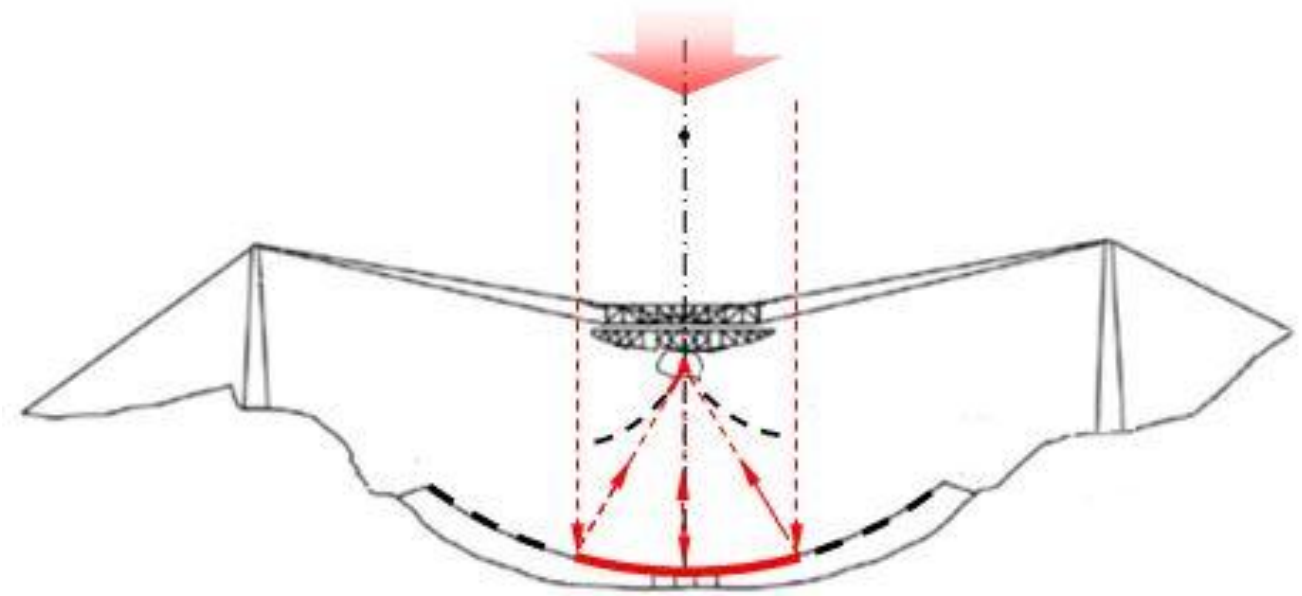

b)

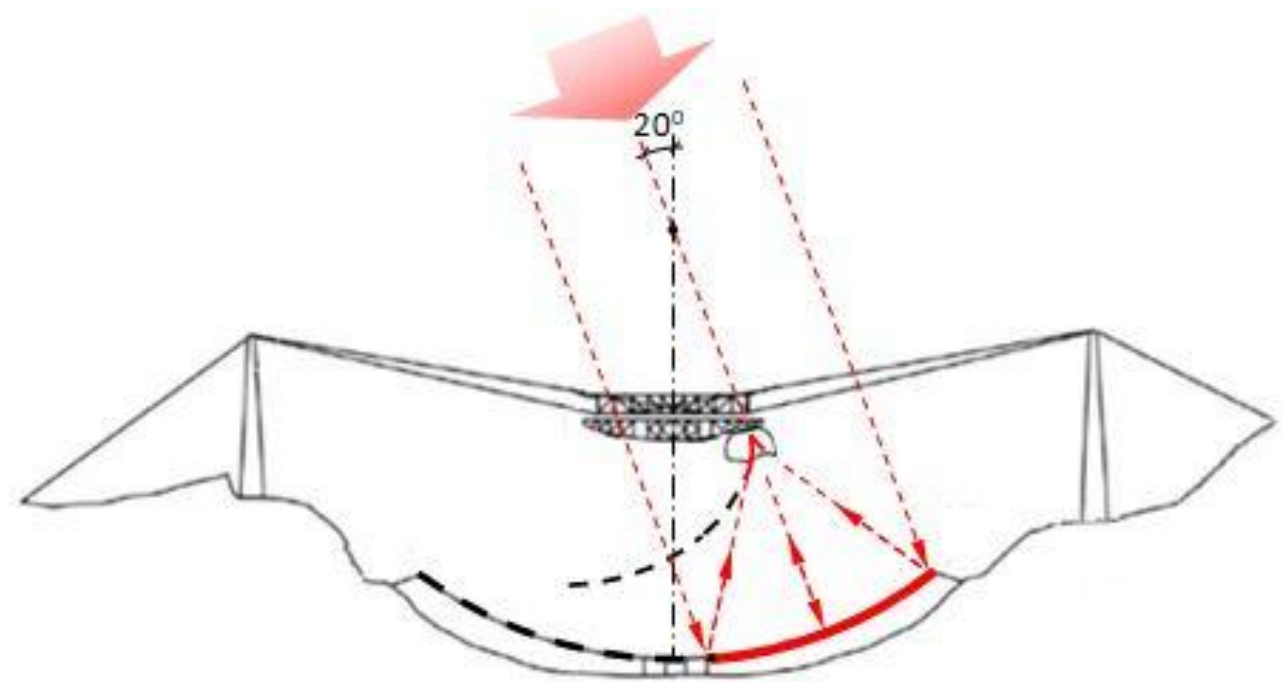

c)

Fig. 13. Bowl of the Arecibo reflector and the caustic it forms. The active part of the reflector and caustics is shown (red). a), b), c): directions of wave arrival $-20^{\circ}, 0^{\circ},+20^{\circ}$ relative to the zenith. Illustrative sketch based on [20]. 


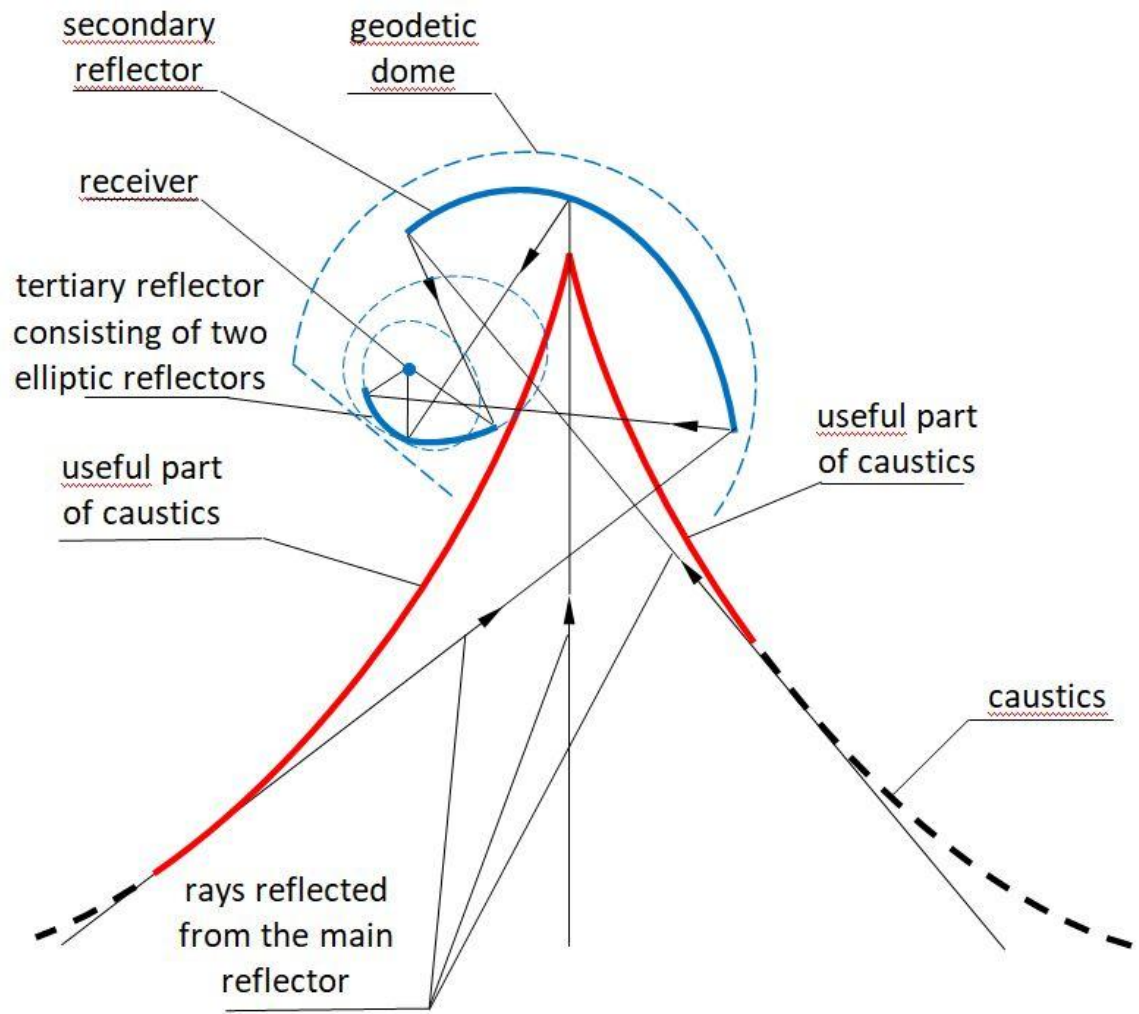

Fig. 14. Ray tracing of the secondary and tertiary reflectors of the Arecibo uses the energy concentrated on the part of caustic marked in red. The pair of ellipses defining the shape of the tertiary reflector is shown.

\section{Parabolic reflector} In 2016, 53 years after the radio telescope in Arecibo was launched, the FAST radio

433 telescope (Five-hundred-meter Aperture Spherical radio Telescope) was put into operation in

434 Dawodang (China). Its antenna with a diameter of $520 \mathrm{~m}$ is a section of a sphere with a radius

435 of $\mathrm{R}_{\mathrm{FAST}}=300 \mathrm{~m}$ (Fig. 15). A receiver weighing 3 tons, which moves over the dish by a sys-

436 tem of cables, enables the observation of radio-sources contained in a cone with an opening 
437 angle of aperture of 80 degrees. The FAST radio telescope is a receiving device, while the

438 Arecibo radio telescope was a transmitting and receiving device [25]. The canopy of the FAST radio telescope consists of 4500 movable elements, the position of which can be corrected in such a way that a selected part of the spherical reflector is transformed into a parabolic reflector segment, including a circle with a diameter of $300 \mathrm{~m}$.

442 The corrected part of the reflector thus creates an aperture with a diameter of $\mathrm{A}_{\mathrm{FAST}}=300 \mathrm{~m}$ 443 and a depth of $D_{\text {FAST }}=40.2 \mathrm{~m}$ [26], which gives an area of approx. 38,000 $\mathrm{m}^{2}$, i.e. approx. $6.7 \%$ of the hemisphere area (Eqs. (49), (50)). This shows a different direction of upgrade of LdV's concept over Arecibo. It involves manipulating the curvature of the reflector, while in

446 Arecibo, the useful range of the caustics was manipulated.

$$
2 \Pi * 1 /\left(2 \mathrm{~A}_{\mathrm{FAST}}\right) * \mathrm{D}_{\mathrm{FAST}}=2 \Pi * 150 * 40.3 \approx 38000 \mathrm{~m}^{2}
$$

$$
\frac{38000}{2 \Pi R_{\text {FAST }}^{2}}=\frac{38000}{2 \Pi 300^{2}}=0.067=6.7 \%
$$
ed as a limitation in the use of a spherical mirror. In the case of a parabolic mirror, such a limitation is a coma aberration. It occurs when the observed object is located off the mirror axis and consists in blurring the focus into a loop caustic called a coma (Fig. 17). In a spherical mirror, aberration is an irremovable element of its functioning, while in a parabolic mirror, it

454 disappears completely with the axial incidence of the rays. In the FAST radio telescope, the coma aberration is limited by positioning the receiver with a few-millimetre accuracy, with a 

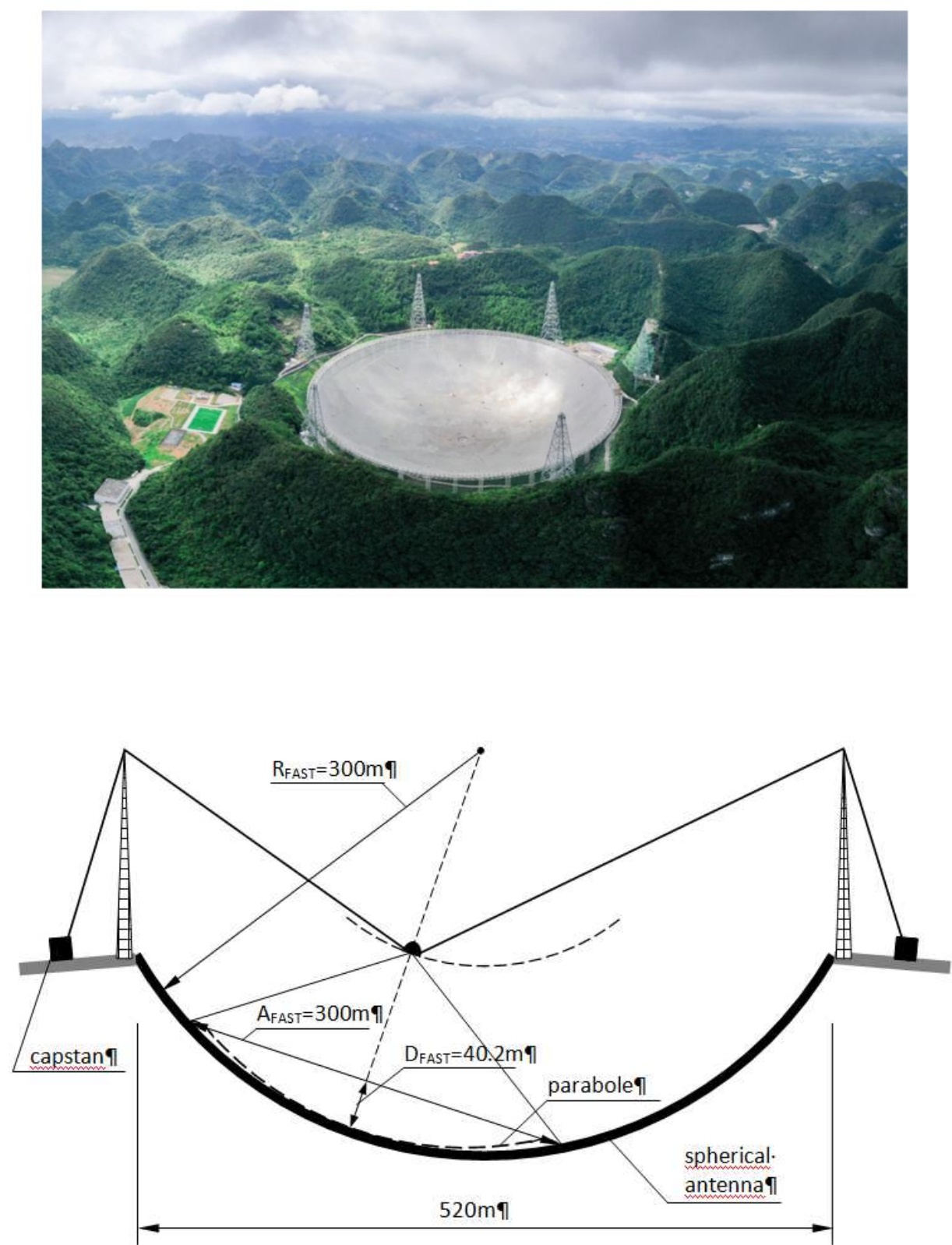


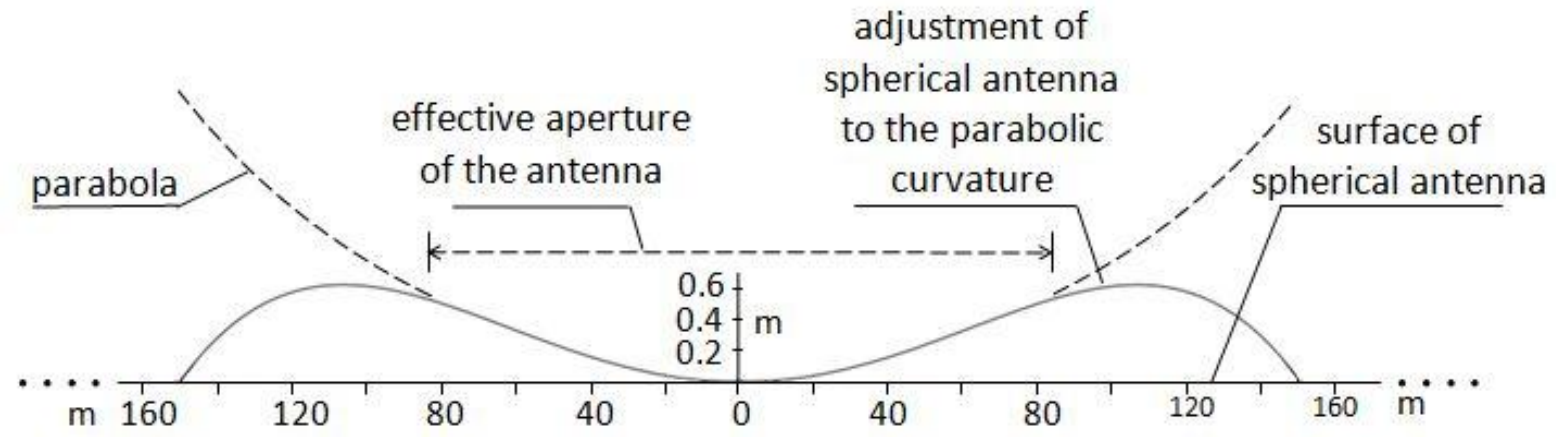

Fig. 16. One of the tested solutions, showing how to adjust a section of the spherical mirror of the

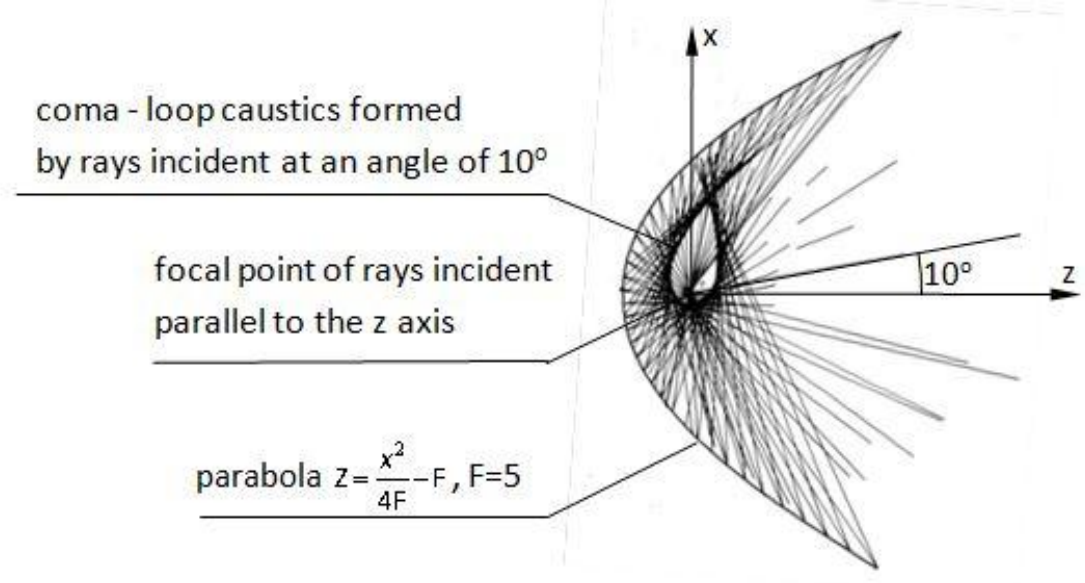

474 Fig. 17. Typical distortion of parabolic mirror in the form of comatic aberration. When the source is

475 located off the mirror axis, the focal point takes the form of a loop caustic, known as a coma [28].

\section{Concluding remarks}

In the achievements of many leading fields of science, you can find ideas from hun- 
480

482

ence of the concept of focussing light through a spherical mirror, formulated by Leonardo daVinci about 500 years ago, in the development of seemingly distant fields of science and technology, such as acoustics and radio astronomy.

Leonardo conducted his theoretical research using a spherical mirror. He showed that less than $0.5 \%$ of the hemisphere area is enough to concentrate energy coming from an infinitely distant source, e.g. from the Sun. With the application of this mirror, the rest of the canopy is useless. This idea, obvious from the point of view of modern knowledge, but formulated 500 years ago, is present today in many areas of technology and science - the aperture of modern spherical mirrors is only a small part of the hemisphere. Their functioning in the field of architectural acoustics, in optical instruments, as antennas in radio telescopes, etc., is fully in line with the $\mathrm{LdV}$ predictions.

During the research on the phenomenon of light concentration, LdV showed a method of graphically determining the surface accompanying the focus, on which the reflected rays are concentrated. This surface is known today as caustics and is present in many fields of technology and science. LdV, however, did not develop the idea of caustics, being apparently unaware of the importance of his discovery. In modern technical knowledge, you can encounter both of the above-mentioned elements of the functioning of mirrors discovered by LdV, i.e. foci and caustics. In the example shown in the article, when the caustic energy is added to the focal energy, the aperture increases from the approx. $0.5 \%$ predicted by LdV to approx. 57\%. After local adjustment of the spherical mirror surface to the curvature of the parabola, the 
500

501

502

503

504

505

506

507

508

509

510

511

512

513

514

515

516

aperture increases to a similar extent. The aperture of the mirror determined by LdV has therefore undergone a significant upgrade as a result of the development of receiving techniques. The technical implementation of the described improvements are the 300-metre radio telescope in Arecibo (Puerto Rico) and the 500-metre FAST radio telescope in Dawodang (China). Internet reports inform about the concept of building a 1000-metre radio telescope, located on the dark side of the Moon away from the Earth's electromagnetic smog, but due to the early stage of this idea, it is not discussed in the article [29].

The caustics found in LdV's drawings are also formed in acoustic field indoors. However, wave phenomena occurring in a room, reverberation and noise floor make it difficult to audibly identify the caustics. As a result, the effect of sound focussing by large curved surfaces in rooms, e.g. arched vaults and concave walls, is reduced to a point focus at the caustic cusp, and the rest of the caustic becomes invisible. For this reason, the concept of caustics is almost unknown in the field of architectural acoustics. 
$521 \quad$ Availability of data and materials

522 Not applicable

523 Ethics declarations

524 Ethics approval and consent to participate

525 Not applicable.

\section{Consent for publication}

$527 \quad$ Not applicable. 


$$
\frac{\mathrm{d}}{\mathrm{dt}} p_{c, \text { res }}(\mathrm{t}, \theta)=\frac{\mathrm{d}}{\mathrm{dt}}\left[\sqrt{\mathrm{I}_{\mathrm{o}} \rho \mathrm{c}_{\mathrm{s}}}\left(\sin \left(\varpi\left(\mathrm{t}+\Delta \mathrm{t}_{1}\right)\right)+\sqrt{\frac{2(1-\alpha) \sin (\theta)}{3\left|\cos ^{3}(\theta)\right|}} \sin \left(\varpi\left(\mathrm{t}+\Delta \mathrm{t}_{2}\right)\right)\right)\right]=
$$

530

$$
\sqrt{\mathrm{I}_{\mathrm{o}} \rho \mathrm{c}_{\mathrm{s}}} \varpi\left(\cos \left(\varpi\left(\mathrm{t}+\Delta \mathrm{t}_{1}\right)\right)+\sqrt{\frac{2(1-\alpha) \sin (\theta)}{3\left|\cos ^{3}(\theta)\right|}} \cos \left(\varpi\left(\mathrm{t}+\Delta \mathrm{t}_{2}\right)\right)\right)=0
$$

$531 \quad$ Substituting

532 yields

533 and after expansion

534

regrouping yields

$$
\frac{\sin (\varpi \tau)}{\cos (\varpi \tau)}=\frac{\frac{1}{b}+\cos \left(\varpi\left(\Delta \mathrm{t}_{1}-\Delta \mathrm{t}_{2}\right)\right)}{-\sin \left(\varpi\left(\Delta \mathrm{t}_{1}-\Delta \mathrm{t}_{2}\right)\right)}
$$

$$
\varpi\left(\mathrm{t}+\Delta \mathrm{t}_{1}\right)=\operatorname{arctg}\left(\frac{\frac{1}{\mathrm{~b}}+\cos \left(\varpi\left(\Delta \mathrm{t}_{1}-\Delta \mathrm{t}_{2}\right)\right)}{-\sin \left(\varpi\left(\Delta \mathrm{t}_{1}-\Delta \mathrm{t}_{2}\right)\right)}\right)
$$

535 and then

536 since

$$
\Delta \mathrm{t}_{1}-\Delta \mathrm{t}_{2}=\frac{\frac{\mathrm{R}}{2}\left(3 \sin \theta-2 \sin ^{3} \theta\right)}{\mathrm{c}_{\mathrm{s}}}-\frac{\frac{\mathrm{R}}{2} 3 \sin \theta}{\mathrm{c}_{\mathrm{s}}}=-\frac{\mathrm{R} \sin ^{3} \theta}{\mathrm{c}_{\mathrm{s}}},
$$

$$
\mathrm{t}=\frac{1}{\sigma} \operatorname{arctg}\left(\frac{\sqrt{\frac{3\left|\cos ^{3} \theta\right|}{2(1-\alpha) \sin \theta}}+\cos \left(\varpi \frac{\mathrm{R} \sin ^{3} \theta}{\mathrm{c}_{\mathrm{s}}}\right)}{\sin \left(\varpi \frac{\mathrm{R} \sin ^{3} \theta}{\mathrm{c}_{\mathrm{s}}}\right)}\right)-\Delta \mathrm{t}_{1}
$$


539

540

541

542

543

544

545

546

547

548

549

550

551

552

553

554

555

556

557

558

559

560

\section{References}

[1] http://www.unmuseum.org/burning_mirror.htm [29.09.2021].

[2] https://en.wikipedia.org/wiki/Ptolemy [29.09.2021].

[3] Dominique Raynaud, The aerial perspective of Leonardo da Vinci and his origins in the optics of Ibn al-haytham (de aspectibus, III, 7) Arabic Sciences and Philosophy 19 (2):225-246 (2009).

[4] Ivanov V.P., Ivanova G.K., Caustic structure of the underwater sound channel. Open Journal of Acoustics, 4, 26-37 (2014) http://file.scirp.org/pdf/OJA_2014032115460011.pdf [29.09.2021].

[5] Khatkevich A.G., Khatkevich L.A., Propagation of laser beams and caustics in crystals. Journal of Applied Spectroscopy, 74, No. 4 (2007)

https://link.springer.com/article/10.1007/s10812-007-0086-8 [29.09.2021].

[6] Skowron J., Analiza niestandardowych zjawisk mikrosoczewkowania grawitacyjnego gwiazd Galaktyki. Rozprawa doktorska (Analysis of non-standard phenomena of gravitational microlensing of Galactic stars. PhD dissertation, in Polish). Uniwersytet Warszawski (2009) http://www.astrouw.edu.pl/ jskowron/PhD/thesis/phd.pdf [13.11.2021].

[7]http://www.bl.uk/turning-the-pages/?id=cb4c06b9-02f4-49af-80ce540836464a46\&type=book, p. 8-15 The Leonardo notebook, pp. 8-15 [29.09.2021].

[8] http://www.bl.uk/turning-the-pages/?id=cb4c06b9-02f4-49af80ce540836464a46\&type $=$ book, \%20p.\%208\%E2\%80\%9314, Leonardo da Vinci’s Codex Arundel, pp. 224-226, 414 [29.09.2021].

[9] http://www.bl.uk/onlinegallery/ttp/leonardo/accessible/pages11and12.html

[10] Kulowski A., The caustic in the acoustics of historic interiors. Applied Acoustics 133, 82-90 (2018) https://doi.org/10.1016/j.apacoust.2017.12.008 [29.09.2021]. 
561 [11] https://www.bl.uk/onlinegallery/ttp/leonardo/accessible/pages13and14.html

562 [12] Kulowski A., Analysis of a caustic formed by a spherical reflector: Impact of a caustic on archi-

563 tectural acoustics, Applied Acoustics 165 (2020),

564 https://doi.org/10.1016/j.apacoust.2020.107333 [29.09.2021].

565 [13] Burkhard D.G., Shealy D.L., Formula for the density of tangent rays over a caustic surface.

566 Applied Optics vol. 21, No. 18, 3299-06 (1982).

567 [14] https://www.gedanopedia.pl/gdansk/?title=Plik:Park_Oliwski_Groty.jpg [16.08.2020].

568 [15] https://dbt.arch.ethz.ch/project/acoustic-mirrors/[16.08.2020].

569 [16] Kladeftira M. et al., Design Strategies for a 3D Printed Acoustic Mirror. Proc. of the 24th

570 CAADRIA Conference - Vol. 1, Victoria University of Wellington, Wellington, New Zealand, 15$571 \quad 18$ April 2019, pp. 123-132].

572 [17] Kladeftira M. et al., Printing whisper dishes. Large-scale binder jetting for outdoor installations.

573 Proc. of the ACADIA 2018 Recalibration: On Imprecision and Infidelity, Proc. of the 38th Annual 574 Conference of the Association for Computer Aided Design in Architecture, 328-35. Mexico City, $575 \quad$ Mexico, October 18-20, 2018.

576 [18] https://www.thoughtco.com/great-domes-from-around-the-world-177717 [29.09.2021].

577 [19] http://poznanfilmcommission.pl/lokacja/aula-uam [21.09.2019].

578 [20] https://www.researchgate.net/figure/A-diagram-of-the-Arecibo-telescope_fig1_2209614 $579 \quad[29.09 .2021]$.

580 [21] Magnani L., The Arecibo 5GHz Mini-Gregorian Feed System; Spectral Line Performance. Publi581 cations of the Astronomical Society of the Pacific, Vol. 105, No. 690, pp. 894-901, August 1993. 
582

583

584

585

586

587

588

589

590

591

592

593

594

595

596

597

598

599

600

601

602

603

[22] https://www.space.com/38217-arecibo-observatory-puerto-rico-telescope-photos.html

[29.09.2021].

[23] Cortés-Medellín G., AOPAF: Arecibo Observatory Phased Array Feed. Internet Publication by National Astronomy and Ionosphere Center Cornell University, Sep 13, 2010 https://www.naic.edu/ phil/hardware/byuPhasedAr/logs/Cortes\%20AOPAF_short\%20report\%20S ept\%202010-1.pdf [29.09.2021].

[24] https://www.nature.com/articles/d41586-019-02790-3 [29.09.2021].

[25] Mathews J.D., (2013), “A short history of geophysical radar at Arecibo Observatory”, History of Geo- and Space Sciences. Vol. 4(1), pp. 19-33. doi:10.5194/hgss-4-19-2013. www.hist-geo-space-sci.net/4/19/2013/hgss-4-19-2013.pdf, doi:10.5194/hgss-4-19$2013[29.09 .2021]$

[26] Nan R., Li D. et al., The Five-Hundred-Meter Aperture Spherical Radio Telescope (FAST) Project, International Journal of Modern Physics D, @World Scientific Publishing Company, Accepted for publication, https://arxiv.org/ftp/arxiv/papers/1105/1105.3794.pdf [29.09.2021].

[27] Williams II R.L., "Five-Hundred Meter Aperture Spherical Radio Telescope (FAST) CableSuspended Robot Model and Comparison with the Arecibo Observatory”, Internet Publication, www.ohio.edu/people/williar4/html/pdf/FAST.pdf, July 2015. [29.09.2021].

[28] Schmidt RF., Analytical caustic surfaces. NASA Technical Memorandum 87805. NASA Technical Reports Server; April 1987. https:/ntrs.nasa.gov/archive/nasa/ casi.ntrs.nasa.gov/19880001678.pdf [29.09.2021].

[29] https://www.nasa.gov/directorates/spacetech/niac/2020_Phase_I_Phase_II/lunar_crater_radio_telescope/ [26.10.2021]. 